\title{
Corrosion Resistance of Alumina-Forming Alloys against Molten Chlorides for Energy Production. I: Pre-Oxidation Treatment and Isothermal Corrosion Tests
}

\author{
J.C. Gomez-Vidal, ${ }^{1, *}$ A.G. Fernandez,,${ }^{1,2}$ R. Tirawat, ${ }^{1}$ C. Turchi, ${ }^{1}$ and W. Huddleston ${ }^{1}$ \\ ${ }^{1}$ National Renewable Energy Laboratory, 15013 Denver West Parkway, Golden, CO 80401 \\ ${ }^{2}$ Energy Development Center, University of Antofagasta, Av. Universidad de Antofagasta \\ 02800, Antofagasta, Chile \\ * Corresponding author: judith.vidal@nrel.gov
}

\section{Abstract}

Advanced components in next-generation concentrating solar power (CSP) applications will require advanced heat-transfer fluids and thermal-storage materials that work from about $550^{\circ} \mathrm{C}$ to at least $720^{\circ} \mathrm{C}$, for integration with advanced power-conversion systems. To reach the cost target, less-expensive salts such as molten chlorides have been identified as high-temperature fluid candidates. High-strength alloys need to be identified and their mechanical and chemical degradation must be minimized to be used in CSP applications. Approaches for corrosion mitigation need to be investigated and optimized to drive down corrosion rates to acceptable levels-in the order of tens of micrometers per year-for achieving a long system lifetime of at least 30 years.Surface passivationis agood corrosion mitigation approach because the alloy could then be exposed to both the liquid and the vapor phases of the salt mixture. In this investigation,we pre-oxidized the alumina-forming alloys Inconel 702, Haynes 224, and Kanthal APMT at different temperatures, dwelling times, and atmospheres to produce the passivation by forming protective oxides at the surface. The pretreated alloys were latercorrodedin molten $\mathrm{MgCl}_{2}-64.41 \mathrm{wt} \% \mathrm{KClat} 700^{\circ} \mathrm{C}$ in a flowing Ar atmosphere. We performed electrochemical techniques such as open-circuit potential followed by a potentiodynamic polarization sweep and conventional long-term weight-change tests to down-select the best-performing alloy and pre-oxidation conditions. The best corrosion results were obtained for $\ln 702$ pre-oxidized in zero air at $1050^{\circ} \mathrm{C}$ for $4 \mathrm{~h}$. Metallographic characterization of the pre-oxidized alloys and of the corroded surfaces showed that the formation of dense and uniform alumina scale during the pre-oxidation appears to protect the alloy from attack by molten chloride.

Keywords - molten salts; corrosion; chlorides; alumina-forming alloys; alumina; oxidation

\section{Introduction}

Molten chlorides are being considered as heat-transfer fluids (HTFs) and thermal energy storage (TES) candidates for advanced high-temperature thermal applications because of their high decomposition temperatures and good thermal properties. Advanced concentrating solar power (CSP) plants are considering the use of these molten salts[1]. This technology requires the use of high-temperature HTFs in the range 
of $550^{\circ} \mathrm{C}$ to $800^{\circ} \mathrm{C}$. In the nuclear energy sector, LiCl-containing salts were considered as coolants and TES media. Chloride molten salts were explored earlier for nuclear applications but because of major drawbacks including the more corrosive characteristics of chloride systems relative to fluoride systems, they were not considered for further nuclear applications [2,3].For CSP, $\mathrm{NaCl}, \mathrm{KCl}, \mathrm{MgCl}_{2}$, and/or $\mathrm{ZnCl}_{2}$ mixturescould be used as the HTF in solar receivers and/or as sensible- or latentTES material. Structural materials are needed for constructing high-temperature thermal components, e.g., heat exchangers, piping, and storage vessels, but molten chlorides are usually corrosive to typical alloys.

The type of corrosion typical of chromia-forming alloys in molten chlorides when a small amount of oxygen is allowed in the system has been reported to be localized, such as intergranular and pitting corrosion [4,5].Groll et al. [4] evaluated the corrosion behavior of steel containers in latent-TES molten eutectic $\mathrm{KCl}-\mathrm{LiCl}$ from $310^{\circ} \mathrm{C}$ to $420^{\circ} \mathrm{C}$ in air and argon with a long-term weight-loss technique up to $4032 \mathrm{~h}$ of immersion time. The effect of water and other impurities in the salt was studied. Pitting corrosion patterns were detected and additions of $2 \mathrm{wt} \% \mathrm{H}_{2} \mathrm{O}$ caused a severe increase in corrosion in these environments. Mechanical failure of components due to localized corrosion (pitting or intergranular) is catastrophic because the failure is usually quick and unexpected. Uniform corrosion, in which the surface gradually degrades, is preferred because it is easy to control. It has been observed that $\mathrm{Cr}$ is commonly depleted near the degradation zone. The corrosion mechanism proposed elsewhere is that $\mathrm{CrCl}_{3}$ formed at the bottom of the pits or degraded grain boundaries, and it rapidly diffused toward the alloy surface. At the fluid/alloy interface, dissolved oxygen is higher in content than at the bottom of the pits. Because of the higher oxygen potential, $\mathrm{CrCl}_{3}$ is oxidized to non-protective and non-adherent $\mathrm{Cr}_{2} \mathrm{O}_{3}$, and chlorine is liberated so that the degradation process continues by forming more $\mathrm{CrCl}_{3}$ [6]. Chromium can cause deterioration of the corrosion resistance in chloride molten salts exposed to oxidizing atmospheres by forming chromates and chromium chlorides that are oxidants and can increase corrosion [7].

Creep-resistant, alumina-forming austenitic (AFA) stainless steels have been successfully developed at Oak Ridge National Laboratory (ORNL), which targeted the high-temperature applications in the range of $\sim 600^{\circ} \mathrm{C}-900^{\circ} \mathrm{C}$ through the guidance of computational thermodynamics. To date, various AFA grades have been developed that include the alloys with higher-temperature oxidation resistances up to $950^{\circ} \mathrm{C}$, low-Nicontaining inexpensive materials, or high creep strength comparable or superior to advanced austenitic stainless steels or Ni-based alloys. Good creep resistance in AFAs is achieved by precipitating multiple types of secondphases [8].

Other iron-and nickel-based alumina-forming alloys (Al-FAs) such as Inconel 702 (In702), Haynes 224 (HR224), and Kanthal APMT are considered for high-temperature 
thermal applications because of their ability to form protective oxide layers on the surface. These alloys exhibit good high-temperature oxidation resistance by forming a protective $\mathrm{Al}_{2} \mathrm{O}_{3}$ scale with excellent chemical and thermal stability. The formation of protective alumina scales at elevated temperatures offers oxidation resistance that is superior to that of chromia-forming conventional stainless steels. Protective alumina scales have been shown to be a more effective barrier to the inward penetration of aggressive components such as chlorine and chloride molten salts [9]. Chromia-forming alloys have been shown to not be corrosion resistant in chloride molten salt environments [10]. Alumina grows at a slower rate than chromia, is more stable thermodynamically with oxygen, and affords a significantly higher degree of protection in the presence of many aggressive oxidizing species. Brady et al. [11] prepared and tested several Al-FAs in aggressive sulfidation-oxidation environments of $\mathrm{Ar}-20 \% \mathrm{H}_{2}-$ $20 \% \mathrm{H}_{2} \mathrm{O}-5 \% \mathrm{H}_{2} \mathrm{~S}$ at $650^{\circ} \mathrm{C}$. The $\mathrm{Fe}-25 \mathrm{Ni}-4 \mathrm{Al}-2.5 \mathrm{Nb}-0.2 \mathrm{C}$ (wt \%) alloy showed the lower corrosion rate of $596 \mu \mathrm{m} /$ year. This alloy was identified as of interest for future scale-up activities.

The molten salt corrosion behavior of $\mathrm{Fe}-\mathrm{Cr}, \mathrm{Fe}-\mathrm{Al}$, and $\mathrm{Ni}-\mathrm{Al}$ alloys was investigated with a surface deposit of $\mathrm{NaCl}-\mathrm{KCl}$ melt in air at $670^{\circ} \mathrm{C}$. Fe-Al alloys improved their corrosion resistance with increasing Al content. Chromium exhibited a detrimental effect on corrosion of $\mathrm{Fe}-\mathrm{Cr}$ alloys under the same conditions. The best corrosion resistance was observed in $\mathrm{Ni}-\mathrm{Al}$ alloys, in which $\mathrm{Ni}$ remained relatively stable in the chloride system [7].

Hellstroom et al. tested the corrosion behavior of pre-oxidized FeCrAl alloy (Kanthal APMT) in $5 \% \mathrm{O}_{2}$ with $40 \% \mathrm{H}_{2} \mathrm{O}$ plus 300 ppm of $\mathrm{SO}_{2}$ at $600^{\circ} \mathrm{C}$ in the presence or absence of $\mathrm{KCl}$. They found that $\mathrm{KCl}$ strongly accelerated the corrosion of the alloy by forming soluble $\mathrm{K}_{2} \mathrm{CrO}_{4}$ and gaseous $\mathrm{HCl}$, depleting $\mathrm{Cr}$ and triggering the formation of a fast-growing iron-rich scale.Adding $\mathrm{SO}_{2}$ suppressed corrosion due to the conversion of corrosive $\mathrm{KCl}$ to stable $\mathrm{K}_{2} \mathrm{SO}_{4}$. They reported that the corrosion rate was significantly lower than that of chromia-forming alloys. Pre-oxidation decreased the corrosion rate even further, making Kanthal APMT a promising candidate material for combustion plant components, particularly from a corrosion point of view [12].

The protective behavior of alumina scales is attributed to the formation of stable $\alpha$ $\mathrm{Al}_{2} \mathrm{O}_{3}$ phase. Several metastable $\mathrm{Al}_{2} \mathrm{O}_{3}$ polymorphs such as $\mathrm{\gamma}$ and $\theta$ phases tend to form in oxidizing environments at temperatures lower than $1,150^{\circ} \mathrm{C} . \alpha-\mathrm{Al}_{2} \mathrm{O}_{3}$ typically forms at longer oxidation times and/or higher temperatures. Metastable $\gamma$ - and $\theta-\mathrm{Al}_{2} \mathrm{O}_{3}$ scales contain lattice defects, so they provide no significant protection to further oxidation of the alloys compared with $\alpha-\mathrm{Al}_{2} \mathrm{O}_{3}$ scale $[13,14]$. The transformation from these metastable phases to $\alpha-\mathrm{Al}_{2} \mathrm{O}_{3}$ can lead to crack formation caused by volume changes ( 13\%) [15]. $\mathrm{Li}$ and Spiegel determined that a dense alumina surface layer was particularly stable in the presence of $\mathrm{KCl}$ vapor [9]. To selectively control the formation of protective $\alpha-\mathrm{Al}_{2} \mathrm{O}_{3}$ 
at lower temperatures, low oxygen partial pressures $\left(\mathrm{pO}_{2}\right)$ can be used. Dense and smooth $\alpha-\mathrm{Al}_{2} \mathrm{O}_{3}$ scales are formed rapidly by treatment at $1050^{\circ} \mathrm{C}$ under low $\mathrm{pO}_{2}$, where both aluminum and chromium in the Al-FAs are oxidized and other elements such as iron and nickel are not. Thermodynamic calculations predicted that only $\alpha-(\mathrm{Al}, \mathrm{Cr})_{2} \mathrm{O}_{3}$ will be produced during the pre-oxidation of CoNiCrAlY under a low oxygen partial pressure $\left(\mathrm{pO}_{2}\right.$ below $\left.10^{-9} \mathrm{~Pa}\right)$ at $1050^{\circ} \mathrm{C}$ for $4 \mathrm{~h}[15,16]$. Pre-oxidation results showed the formation of a dense $\alpha-\mathrm{Al}_{2} \mathrm{O}_{3}$ scale with large grains. By contrast, under a higher $\mathrm{pO}_{2}$ (above $10^{-9} \mathrm{~Pa}$ ), all the components in the alloy were oxidized and formed a nonprotective mixed-oxide scale including metastable $\theta-\mathrm{Al}_{2} \mathrm{O}_{3}[13,15,16]$. It has been reported that adding chromium or iron to Al-FAs accelerates the transformation from metastable polymorphs to $\alpha-\mathrm{Al}_{2} \mathrm{O}_{3}[17-20]$.

Kanthal APMT is a FeCrAIMo alloy optimized for continuous service up to $1250^{\circ} \mathrm{C}$. This alloy exhibits an attractive combination of resistance to oxidation and corrosion and good mechanical properties at elevated temperatures. This is due to the oxidedispersion-strengthened (ODS) microstructure obtained from rapid solidification powder metallurgy. Jönsson et al. determined that the adherent alumina layer formed during service provided excellent resistance to corrosion attacks in most industrial atmospheres and gave great advantages compared to chromia-forming hightemperature Ni-based alloys in terms of maximum operating temperature and life. The high creep resistance allows for design of moderately loaded components up to the maximum recommended continuous operation temperature of $1250^{\circ} \mathrm{C}$ [21].

Weight-loss corrosion techniques are very accurate but are time-intensive. To obtain corrosion rates, more than $500 \mathrm{~h}$ of immersion time is usually required [5]. The use of electrochemical techniques allows continuous corrosion evaluation, as well as the determination of instantaneous corrosion rates, corrosion mechanisms, and processcontrolling steps after only a few hours of testing. These techniques have been employed for a better understanding of the fundamentals behind the corrosion mechanisms for molten-salt electrolytes [6,22-26]. Potentiodynamic polarization sweep (PPS) is commonly employed to determine the corrosion rate of materials. Before polarizing the sample by applying the cathodic and anodic over-potentials, the system must establish the open-circuit potential (OCP), which is the equilibrium potential for the undisturbed system.

The PPS diagrams, which plot the applied potential versus log-scale of measured current density, are used to determine the corrosion current $\left(I_{\text {corr }}\right)$ that is found at the interception of the extrapolated linear or Tafel portions of the cathodic and anodic curves (usually found in the linear portions between $-250 \mathrm{mV}$ and $+250 \mathrm{mV}$ relative to the OCP or corrosion potential ( $\left.E_{\text {corr }}\right)$ of the sample) $[5,6,10,25,26]$.

The corrosion rate is calculated using the Stern-Geary equation through Faraday's Law as follows [27]: 


$$
C R=\frac{I_{\text {corr }} \cdot K \cdot E W}{\rho A},
$$

where $C R$ is the corrosion rate $(\mu \mathrm{m} / \mathrm{yr}), K$ is a constant equal to $3,272 \times 10^{3}$ $[\mu \mathrm{m} /(\mathrm{A} \cdot \mathrm{cm} \cdot \mathrm{yr})], E W$ is the equivalent weight of the alloy (g/equivalent), $\rho$ is the alloy density $\left(\mathrm{g} / \mathrm{cm}^{3}\right)$, and $A$ is the exposed surface area $\left(\mathrm{cm}^{2}\right)$.

The equivalent weight for alloys is calculated as follows:

$$
\begin{aligned}
& E W=N E Q^{-1} \\
& N E Q=\sum\left(\frac{f_{i} \cdot n_{i}}{M W_{i}}\right),
\end{aligned}
$$

whereNEQ is the number of equivalent, $f_{i}$ is the weight fraction, $n_{i}$ is the number of electrons being transferred, and $M W_{i}$ is the atomic weight.

Morks et al. [28] determined the protective nature of plasma-sprayed alumina-coated mild steel in aqueous chloride corrosive environments at room temperature by employing OCP, PPS, and electrochemical impedance spectroscopy (EIS). They found that alumina-coating reduced the corrosion rate of the steel from 3,110 $\mu \mathrm{m} / \mathrm{yr}$ (bare) to $240 \mu \mathrm{m} / \mathrm{yr}$ (coated).

In this work, the National Renewable Energy Laboratory (NREL) evaluated the corrosion resistance behavior of Al-FAs (In702, HR224, and APMT) pre-oxidized in argon and zero air (ZA) and corroded in molten 35.59 wt. $\% \mathrm{MgCl}_{2}-64.41 \mathrm{wt} . \% \mathrm{KCl}\left(\mathrm{T}_{\mathrm{m}}\right.$ $=423^{\circ} \mathrm{C}$ )at $700^{\circ} \mathrm{C}$ in a flowing $\operatorname{Ar}(99.9999 \%)$ atmosphere. The conventional weightchange technique up to $500 \mathrm{~h}$ and electrochemical techniques were employed.

\section{Material and methods}

\subsection{Preparation of salt mixture}

The eutectic $\mathrm{MgCl}_{2}-\mathrm{KCl}$ was prepared using singlecomponents with a purity greater than 99 wt\%acquired from Alfa Aesar. Because $\mathrm{MgCl}_{2}$ is highly hygroscopic, the salts were kept in a vacuum furnace at $120^{\circ} \mathrm{C}$ for at least $48 \mathrm{~h}$ before mixing. The dried salts were weighed and mixed to the proper ratio in 125-g batches in a glove box under dry nitrogen. The salts were then placed in a boron nitride crucible because this material previouslywas shown to be stable in chloride molten-salt systems. The salt mixture was placed in thevacuum furnace at $120^{\circ} \mathrm{C}$ for at least 24 hprior to the pre-melting and purification process.

The following purification process was used during pre-melting of the salt: 1) purge $100 \mathrm{sccm}$ of $\mathrm{Ar}$ through salt while holding at $100^{\circ} \mathrm{C}$ for $5 \mathrm{~h} ; 2$ ) raise the temperature to $200^{\circ} \mathrm{C}$ for $2 \mathrm{~h}$; 3) raise to $300^{\circ} \mathrm{C}$ for $2 \mathrm{~h} ; 4$ ) raise to $400^{\circ} \mathrm{C}$ and hold until Ar purge tube can be removed; 5) because $\mathrm{MgCl}_{2}$ melts at $\sim 714^{\circ} \mathrm{C}$, increase temperature to $800^{\circ} \mathrm{C}$ and hold it for $1 \mathrm{~h}$ to guarantee good mixing. The BN crucible also was shown to not be wetted by the chlorides, so removal of the salt after solidification was much easier. To 
1 avoid moisture absorption after cooling, the pre-melted and solidified salt was stored at

$2120^{\circ} \mathrm{C}$ in the vacuum furnace until needed for testing.

$3 \quad 2.2$ Alloy preparation and pre-oxidation

4

Table 1 shows the nominal composition of Al-FAs tested. Samplesof $12 \times 25 \times 3$ $(\mathrm{mm})$ were used for electrochemical tests while $12 \times 12 \times 3(\mathrm{~mm})$ was used for weightchange long-term tests. The samples required for electrochemical corrosion testswere progressively polished using up to a 1200-grit SiC abrasive paper, cleaned with deionized water, and dried with acetone and compressed air. Polishing is required before electrochemical corrosion tests to control the amount of flat surface area exposed to the corroding fluidthat is used to normalize the corrosion current density of the samples.

Table 1. Candidate alumina-forming alloys chemical composition and mechanical properties. UTS: ultimate tensile strength; YS: yield strength.

\begin{tabular}{|c|c|c|c|c|c|c|c|c|c|}
\hline \multirow{3}{*}{$\begin{array}{c}\text { Alloy } \\
\text { Haynes } \\
224\end{array}$} & \multicolumn{5}{|c|}{ Composition, wt\% } & \multicolumn{4}{|c|}{ Mechanical Properties, MPa } \\
\hline & \multirow{2}{*}{$\begin{array}{c}\mathrm{Ni} \\
46 . \\
4\end{array}$} & \multirow{2}{*}{$\begin{array}{c}\mathrm{Cr} \\
20.5\end{array}$} & \multirow{2}{*}{$\begin{array}{l}\text { Al } \\
3.2\end{array}$} & \multirow{2}{*}{$\begin{array}{c}\mathrm{Fe} \\
27.6\end{array}$} & \multirow{2}{*}{$\begin{array}{c}\text { Other } \\
0.2 \mathrm{Mo}, 0.3 \mathrm{Mn}, \\
0.3 \mathrm{Si}, 0.4 \mathrm{Ti}, 0.4 \mathrm{Co}\end{array}$} & \multicolumn{2}{|c|}{$\begin{array}{l}\text { UTS } \\
\left(\mathrm{T},{ }^{\circ} \mathrm{C}\right)\end{array}$} & \multicolumn{2}{|c|}{$\begin{array}{c}2 \%_{\text {offset }} Y S \\
\left(\mathrm{~T},{ }^{\circ} \mathrm{C}\right)\end{array}$} \\
\hline & & & & & & $\begin{array}{c}575 \\
(650)\end{array}$ & $\begin{array}{c}499 \\
(760)\end{array}$ & $\begin{array}{l}398 \\
(650)\end{array}$ & $\begin{array}{c}420 \\
(760)\end{array}$ \\
\hline $\begin{array}{l}\text { Kanthal } \\
\text { APMT }\end{array}$ & - & 21 & 5 & $\sim 70$ & 3Mo & $\begin{array}{c}420 \\
(600)\end{array}$ & $\begin{array}{l}120^{*} \\
(800)\end{array}$ & & . \\
\hline $\begin{array}{c}\text { Inconel } \\
702\end{array}$ & $\sim 75$ & $\begin{array}{c}14- \\
17\end{array}$ & $\begin{array}{c}2.75- \\
3.75\end{array}$ & 2 & $\begin{array}{c}0.2 \mathrm{Mo}, 0.7 \mathrm{Mn} \\
0.7 \mathrm{Ti}\end{array}$ & $\begin{array}{c}620 \\
(650)\end{array}$ & $\begin{array}{l}550 \\
(760)\end{array}$ & $\begin{array}{c}550 \\
(650)\end{array}$ & $\begin{array}{c}482 \\
(760)\end{array}$ \\
\hline
\end{tabular}

*: No data are available at $760^{\circ} \mathrm{C}$ for comparison with the other alloys. The maximum CSP operating temperature is expected to be around $730^{\circ} \mathrm{C}$.

Note: Alloys were selected based on similar UTS and YS values to those of other high-strength alloys. These alloys are usually $\mathrm{Ni}$-superalloys, Incoloy $800 \mathrm{H}$, and high-stainless steel.

The test matrix of pre-oxidation conditions is shown in Table 2. Down-selection of the best pre-oxidation conditions per alloy was performed based on corrosion rates obtained from PPS tests. These pre-oxidation conditions were used to study in detail the formation of a protective scale. The rate of protective scale formation was evaluated for best pre-oxidation condition (temperature, atmosphere) per alloy that gave the lower corrosion rate. Each alloy was subjected to pre-oxidation for certain periods of time.

\subsection{Corrosion evaluations}

\subsubsection{Electrochemical techniques}

PPS and OCP were used to determine the Tafel slopes and corrosion rates of AlFAs after $4 \mathrm{~h}$ of immersion in molten $\mathrm{MgCl}_{2}-64.41$ wt. $\% \mathrm{KCl}$ at $700^{\circ} \mathrm{C}$ in flowing $\mathrm{Ar}$ (99.9999\%). The data handling used to calculate these values is reported elsewhere [10]. To form the required protective alumina layer oxide at the surface of the alloys, they were pre-oxidized following conditions from Table 2 . The electrochemical cell experimental set-up used in this work is given elsewhere [10, 29]. A crucible electrical 
resistance furnace was used to contain the cell made of 316L. The electrochemical cell contains a quartz liner and an off-gas treatment to trap the chloride by-products. A three-electrode arrangement was used with the working electrode (WE) as the sample, the pseudo reference electrode (RE) made from 0.5-mm-diameter platinum wire, and the counter electrode (CE) made from platinum mesh. The required stability time of 45 min for the pseudo-Pt RE in the chloride molten salt was determined in a previous work [10]. The electrochemical tests were performed using a potentiostat (AUTOLABPGSTAT302N).

Table 2.Test matrix for pre-oxidation conditions.

\begin{tabular}{cccccc}
\hline & & \multicolumn{4}{c}{ Conditions: $\mathbf{T}\left({ }^{\circ} \mathbf{C}\right), \mathbf{t}(\mathbf{h})$} \\
Atmosphere & Alloy & $\mathbf{1}$ & $\mathbf{2}$ & $\mathbf{3}$ & $\mathbf{4}$ \\
\hline \multirow{2}{*}{ Zero Air $\left(80 \% \mathrm{~N}_{2}\right.}$, & HR224 & 1050,4 & 950,8 & 950,20 & \\
$\left.20 \% \mathrm{O}_{2}\right)$ & APMT & 1050,8 & 950,8 & 950,20 & \\
& In702 & 1050,4 & 1050,8 & 950,8 & 950,20 \\
\hline \multirow{3}{*}{ Pure Ar $(99.9999 \%)$} & HR224 & 1050,4 & 950,8 & 950,20 & \\
& APMT & 1050,8 & 950,8 & 950,20 & \\
& In702 & 1050,4 & 1050,8 & 950,8 & 950,20 \\
\hline
\end{tabular}

For the PPS experiments, the WE'spotential (E) was continuously recorded starting immediately after its salt immersion until $\mathrm{dE} / \mathrm{dt} \leq 100 \mu \mathrm{V} /$ swas obtained, and thus, OCP was established.The PPS testwas conducted immediately afterby applying cathodic (-) and anodic (+) external potentials from $-0.35 \mathrm{~V}$ to $+0.6 \mathrm{~V}$ around the OCP or corrosion potential at $0.001 \mathrm{~V}$ steps and $0.001 \mathrm{~V} / \mathrm{s}$. More than five coupons per test were performed under the same conditions to evaluate the reproducibility of the results. Some results were discarded based on PPS curve behavior. The corrosioncurrent density, $j_{\text {corr }}$, was calculated from the intersectionof the extrapolated straight sections of the cathodicand anodic Tafel slopes within an interval of $120 \mathrm{mV}$ with respect to $E_{\text {corr. }}$

\subsubsection{Weight-change long-term tests}

A controlled atmosphere tube furnace was used for the weight gain/loss tests. Down-selection of the best pre-oxidation conditionsper alloy was previously determined from PPS and OCP tests. Two replicates per sample were placed in quartz crucibles (10 $\mathrm{cm}^{3}$ of volume) with about $10 \mathrm{~g}$ of purified, pre-melted and solidified salt. The tests were performedat $700^{\circ} \mathrm{C}$ in flowing Arduring 175, 325, and $505 \mathrm{~h}$. After each period of time,the samples were removed from the salt and cleaned using ASTM G1-03. Mass changewas recorded and thickness loss was calculated.

\subsection{Characterization of the alloys and salts}

The samples were metallographically characterized before and after pre-oxidization and after corrosion testswith X-ray diffraction (XRD) and field-emission scanning electron microscopy (FESEM) with energy-dispersive X-ray spectrometry (EDX).Salt 
1 specimens from the purified salt and those being removed from progressive long-term 2 immersion stages were dissolved in an acidic medium. The solutions were analyzed by

3 inductively coupled plasma mass spectroscopy (ICP-MS) to determine chemical

4 composition.

5 3. Results and discussion

\subsection{Oxidation of Al-FAs to form protective oxide layers}

XRD was used to identify the phases formed after oxidation of HR224, In702, and APMT in ZA and Ar. Figures $1-3$ show the XRD patterns and the identified crystalline phases. Using X'PertHighScore Plus software, the patterns resolved the corundum $\alpha$ aluminacrystalline structure. In some cases, $\mathrm{Cr}(0.052-0.1$ molar fraction) substituted Al atoms into the corundum structure forming the aluminum chromium oxide. Single or combined oxides containing $\mathrm{Fe}, \mathrm{Ni}$, and/or $\mathrm{Cr}$ were identified.Since these oxides are much less protective than alumina, it is expected that the zone containing them will corrode first. If a uniform and dense internal layer of protective alumina is formed underneath these oxides, it ishypothesized that the corrosion will be delayedand thus corrosion could be controlled by the presence of a protective alumina layer.

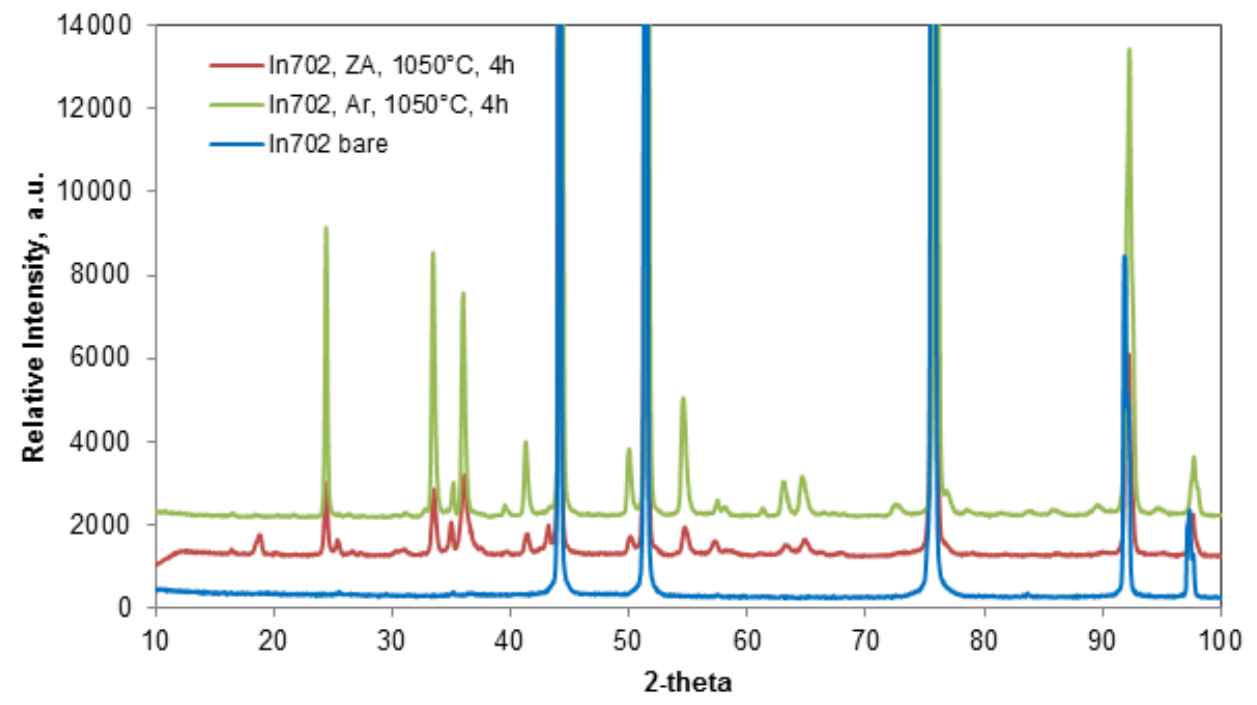

17

\begin{tabular}{ccll}
\hline Sample & Ref. Code & \multicolumn{1}{c}{ Compound Name } & \multicolumn{1}{c}{ Chemical Formula } \\
\hline In702 bare & $00-033-0945$ & austenitic steel & $\mathrm{Ni}_{2.9} \mathrm{Cr}_{0.7} \mathrm{Fe}_{0.36}$ \\
& $03-065-5559$ & Chromium Nickel & $\mathrm{Cr}_{1.12} \mathrm{Ni}_{2.88}$ \\
\hline \multirow{2}{*}{ In702, ZA, } & $00-035-1112$ & Chromium Iron Oxide & $\mathrm{Cr}_{1.3} \mathrm{Fe}_{0.7} \mathrm{O}_{3}$ \\
$1050^{\circ} \mathrm{C}, 4 \mathrm{~h}$ & $00-051-1394$ & Corundum - Aluminum Chromium Oxide & $\mathrm{\alpha}-\left(\mathrm{Al}_{0.9} \mathrm{Cr}_{0.1}\right)_{2} \mathrm{O}_{3}$ \\
& $01-085-1828$ & Hercynite & $\mathrm{Al}_{2} \mathrm{Fe} \mathrm{O}_{4}$ \\
\hline $\ln 702, \mathrm{Ar}$, & $01-084-0311$ & Iron Oxide & $\mathrm{Fe}_{2} \mathrm{O}_{3}$ \\
$1050^{\circ} \mathrm{C}, 4 \mathrm{~h}$ & $00-046-1212$ & Corundum & $\alpha-\mathrm{Al}_{2} \mathrm{O}_{3}$ \\
\hline
\end{tabular}

Fig.1. XRD patterns and identified phases of In702 bare and oxidized in zero air (ZA) and argon 


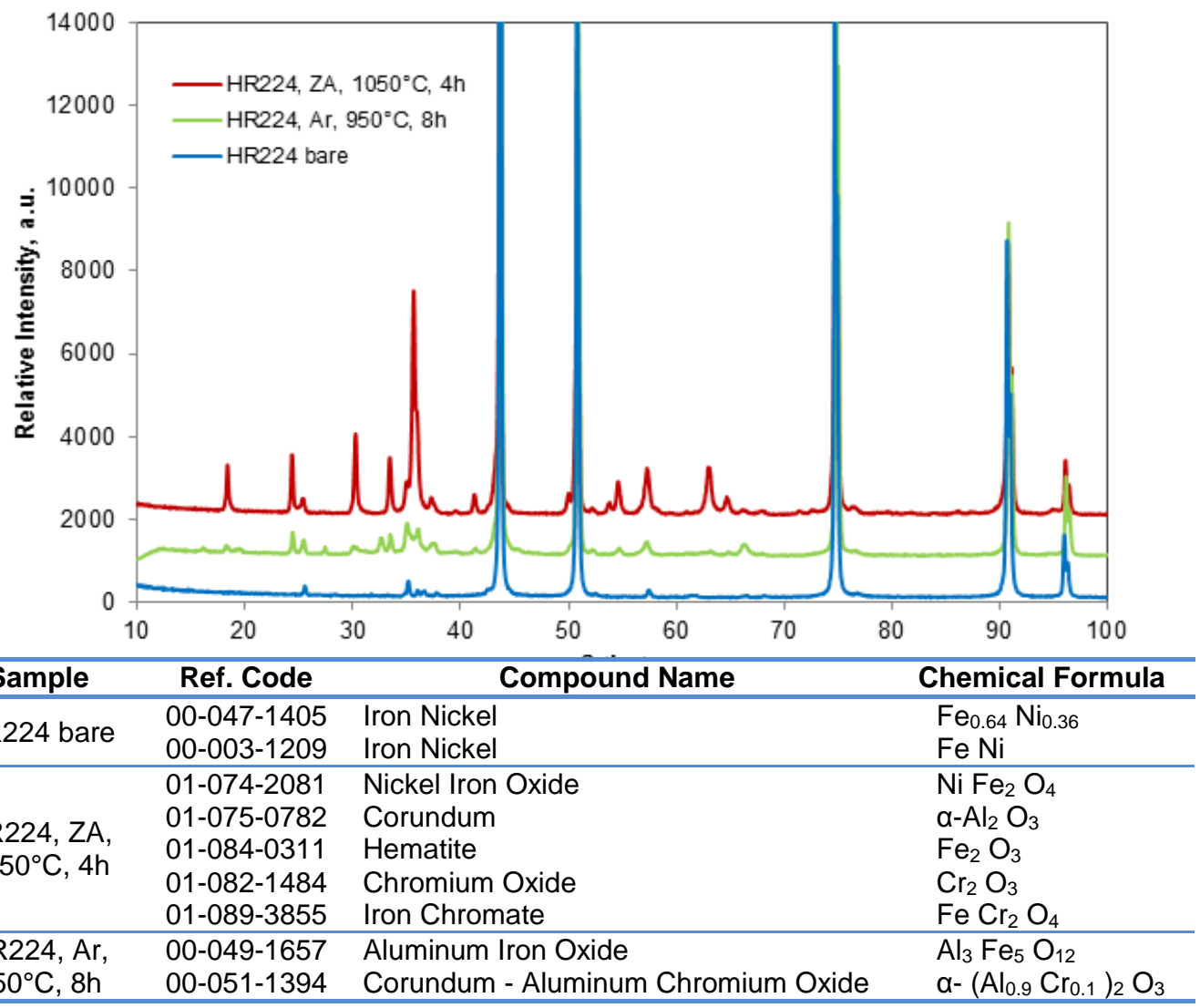

Fig.2. XRD patterns and identified phases of HR224 bare and oxidized in zero air (ZA) and $\operatorname{argon}(\mathrm{Ar})$.

$\mathrm{XRD}$ is a qualitative analysis in which the presence of crystalline phases isresolved. To determine the relative proportion and the morphology of the oxides, cross-section metallography was performed.FESEM analyses were used to determine the surface cross-section microstructure. EDS mapping analyses were performed to determine the distribution of elements such as $\mathrm{C}$ (from the encapsulation), $\mathrm{O}, \mathrm{Fe}, \mathrm{Ni}, \mathrm{Cr}$, and $\mathrm{Al}$. This was used to help determine the best conditions to produce uniform layers of protective alumina and determine the growthpattern of this oxide.

Figures 4 - 6 show the FESEM micrographs and EDS elemental maps of Al-FA with the best-performing pre-oxidation conditions determined during this investigation based on preliminary potentiodynamic polarization sweep (PPS) electrochemical corrosion tests. In all the cases, chromia $\left(\mathrm{Cr}_{2} \mathrm{O}_{3}\right)$ appears as the top layer with alumina (pure or with $\mathrm{Cr}$ substitution) as the internal layer. Alumina grows in In702 as a dispersed phase surrounded by an enriched Ni matrix (Figs. 4a and 4b). HR224 produces powdery/granular alumina phases (Figs. $5 \mathrm{a}$ and $5 \mathrm{~b}$ ). ( $\mathrm{Al}, \mathrm{Cr})_{\mathrm{x}} \mathrm{O}_{\mathrm{y}}$ oxides are mixed with high concentrations of $\mathrm{Cr}$ (Fig. 5a). It appears that the alumina layers formed in KanthalAPMT (Figs. 6a and 6b) are denser and more uniform than in the other Al-FAs. In all cases, alumina layers are only a few micrometers thick. 


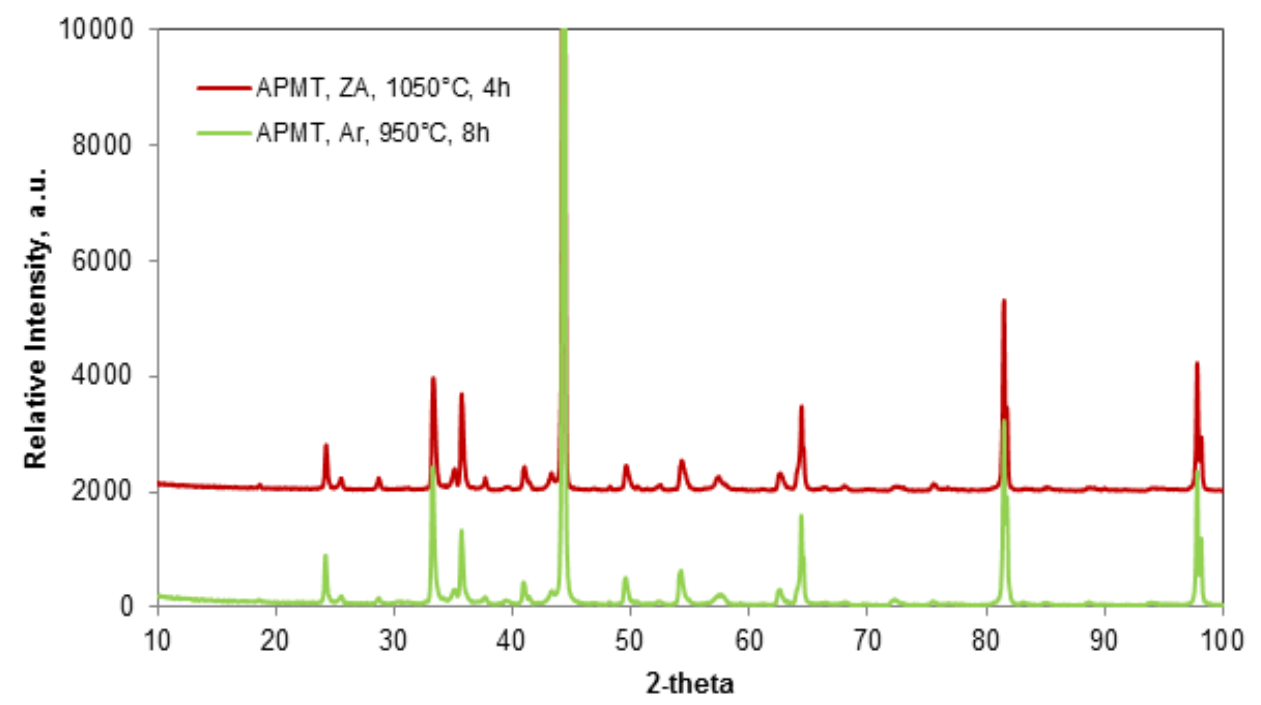

\begin{tabular}{ccll}
\hline Sample & Ref. Code & \multicolumn{1}{c}{ Compound Name } & Chemical Formula \\
\hline \multirow{2}{*}{ Substrate } & $01-085-1410$ & Iron & $\mathrm{Fe}$ \\
& $00-045-0982$ & Aluminum Iron & $\mathrm{Al}_{0.4} \mathrm{Fe}_{0.6}$ \\
\hline APMT, ZA, & $01-089-0599$ & Hematite & $\mathrm{Fe}_{2} \mathrm{O}_{3}$ \\
$1050^{\circ} \mathrm{C}, 4 \mathrm{~h}$ & $01-071-0958$ & Corundum - Aluminum Chromium Oxide & $\left(\mathrm{Al}_{0.948} \mathrm{Cr}_{0.052}\right)_{2} \mathrm{O}_{3}$ \\
\hline APMT, Ar, & $01-089-0596$ & Hematite & $\mathrm{Fe}_{2} \mathrm{O}_{3}$ \\
$950^{\circ} \mathrm{C}, 8 \mathrm{~h}$ & $00-051-1394$ & Corundum - Aluminum Chromium Oxide & $\left(\mathrm{Al}_{0.9} \mathrm{Cr}_{0.1}\right)_{2} \mathrm{O}_{3}$ \\
\hline
\end{tabular}

Fig.3. XRD patterns and identified phases of Kanthal APMT oxidized in zero air (ZA) and argon

(Ar).
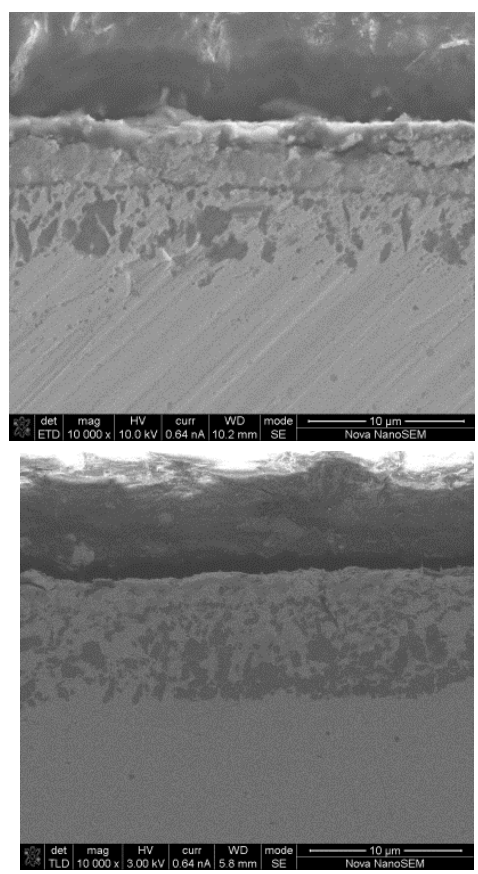
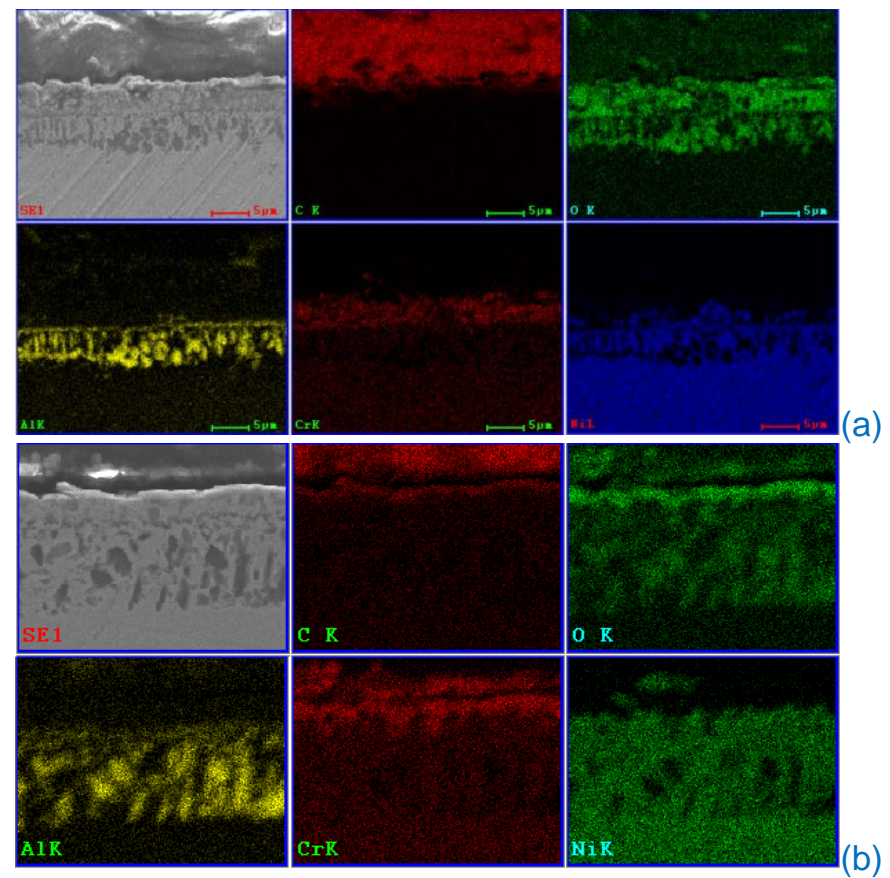

Fig. 4.Down-selected pre-oxidized In702. Left: FESEM-BSE micrograph, right: EDS maps: (a) (ZA, $\left.1050^{\circ} \mathrm{C}, 4 \mathrm{~h}\right),(\mathrm{b})\left(\mathrm{Ar}, 1050^{\circ} \mathrm{C}, 4 \mathrm{~h}\right)$. 

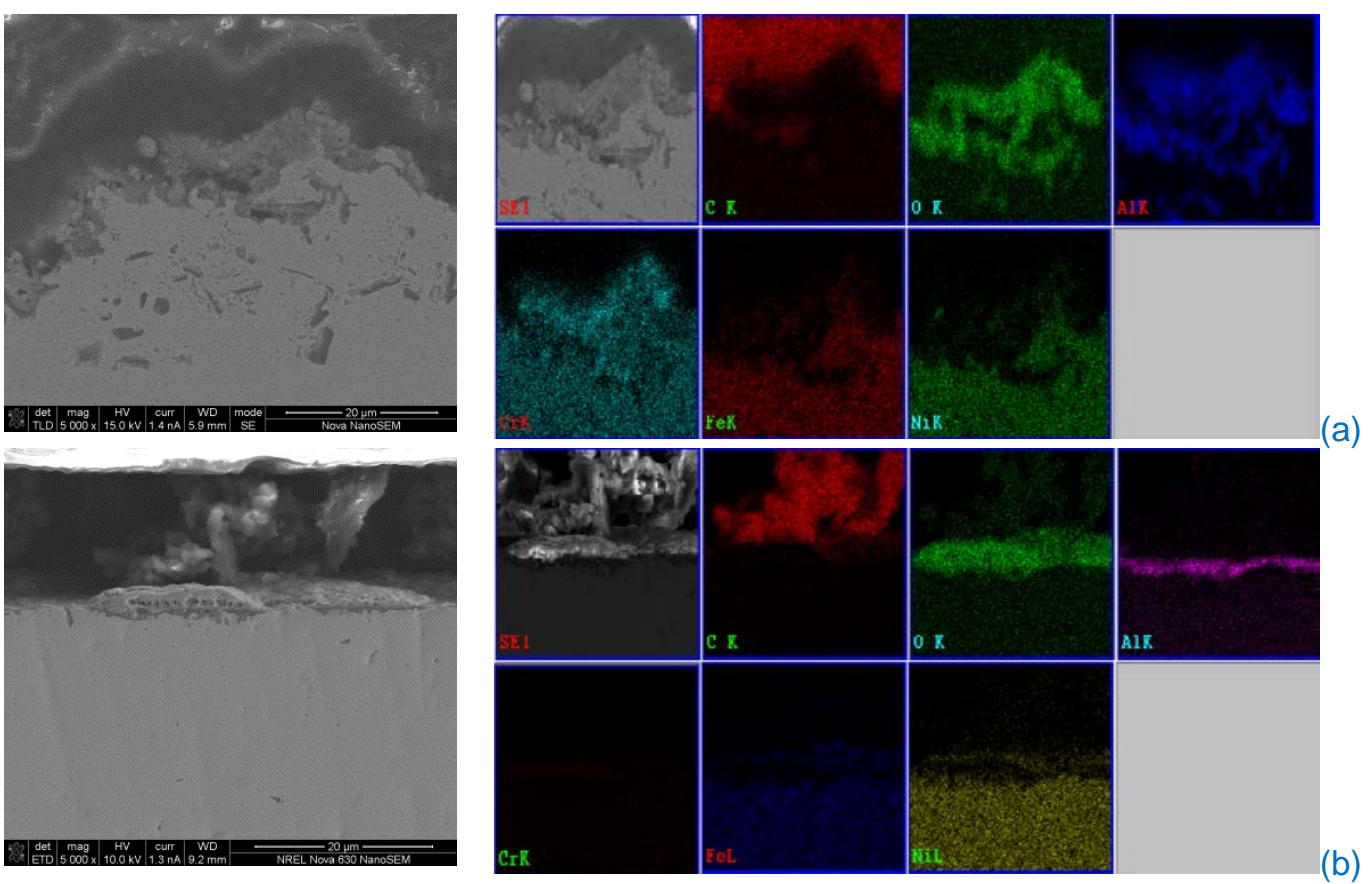

Fig. 5. Down-selected pre-oxidized HR224. Left: FESEM-BSE micrograph, right: EDS maps: (a) $\left(\mathrm{ZA}, 1050^{\circ} \mathrm{C}, 4 \mathrm{~h}\right),(\mathrm{b})\left(\mathrm{Ar}, 950^{\circ} \mathrm{C}, 8 \mathrm{~h}\right)$.
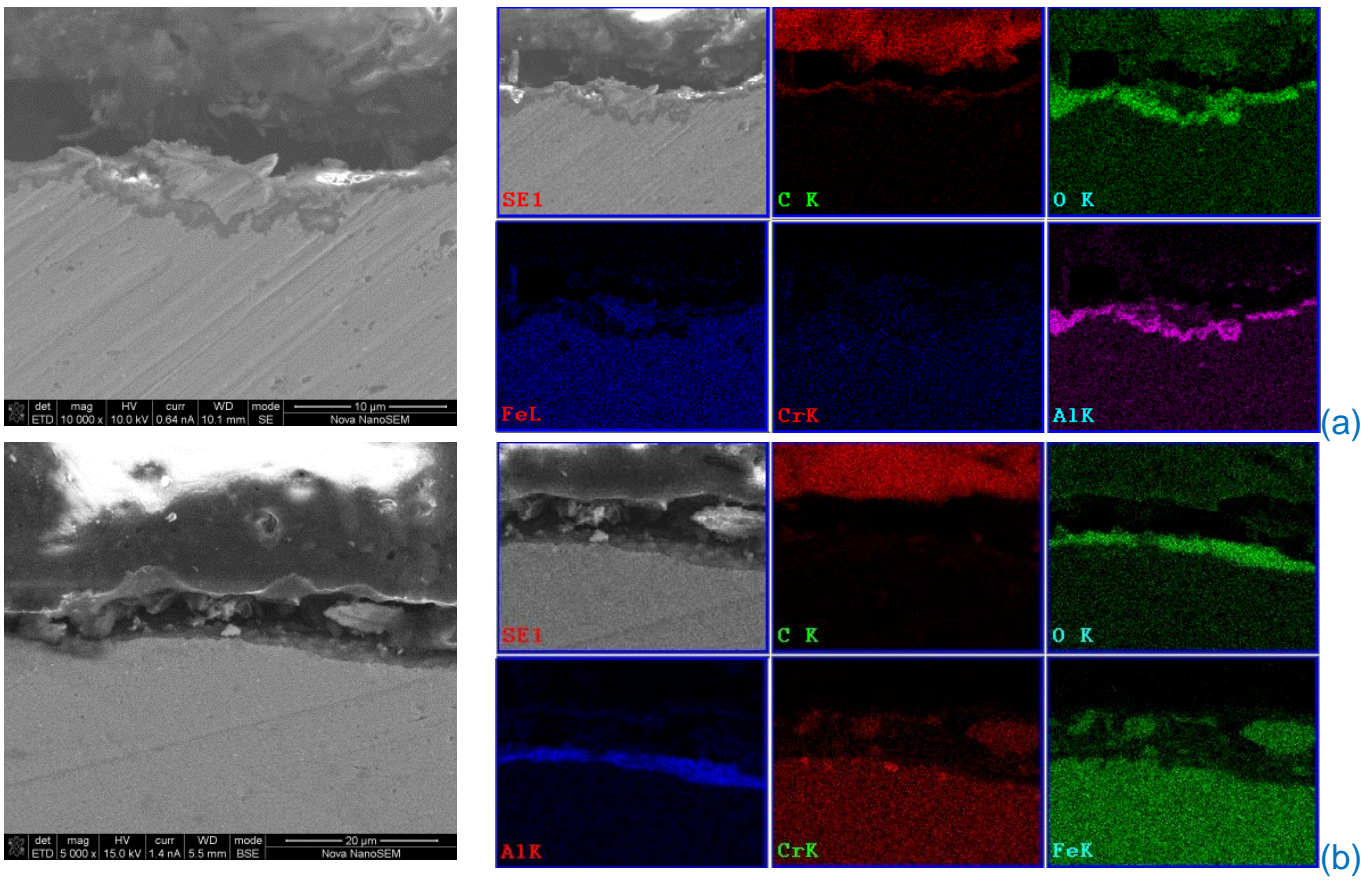

3 Fig. 6.Down-selected pre-oxidized APMT. Left: FESEM-BSE micrograph, right: EDS maps: (a) (ZA,950 $\left.{ }^{\circ} \mathrm{C}, 8 \mathrm{~h}\right),(\mathrm{b})\left(\mathrm{Ar}, 950^{\circ} \mathrm{C}, 8 \mathrm{~h}\right)$.

5 The thickness of aluminum oxide layers was measured and averaged using the

6 FESEM/EDS micrographs and maps as a function of oxidation time up to $25 \mathrm{~h}$. Figure 7 7 shows the averaged alumina thickness with trend lines as a function of time for each 
oxidized Al-FA. Oxidation of In702 in ZA, HR224 in Ar, and APMT in ZA follow the parabolic rate law: $\left(x^{2}=2 k_{p} \cdot t\right)$, where $x$ : oxide film thickness; $t$ : time, and $k_{p}$ : diffusion rate constant (directly proportional to diffusivity of ionic species that is the rate controlling step). The parabolic rate law is typical for protective oxides. The other oxidation for In702 in Ar, HR224 in ZA, and APMT in Ar followa linear rate law which is an empirical relationship that is applicable to the formation and build-up of a nonprotective oxide layer [30].

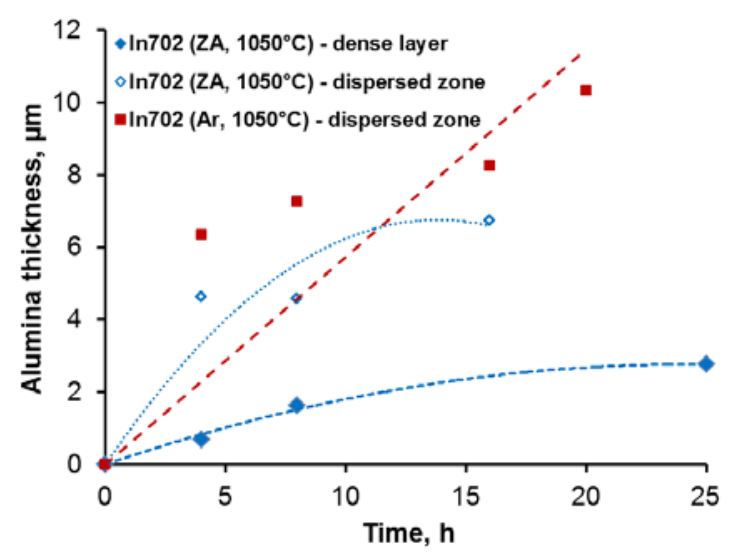

(a)

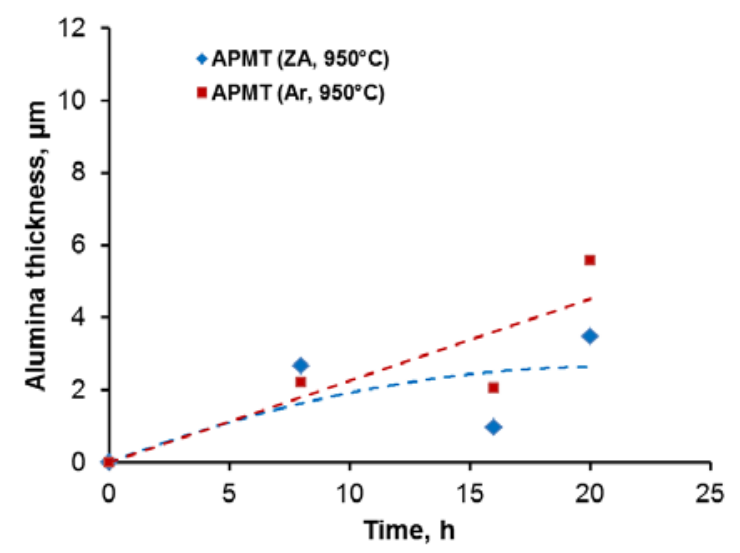

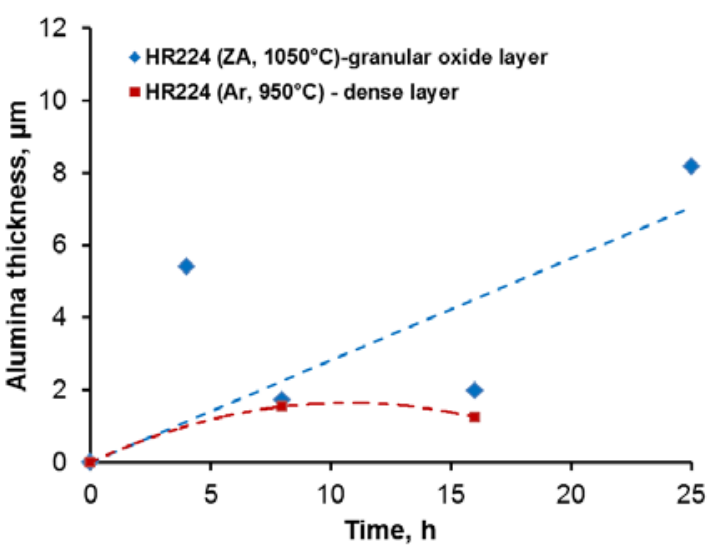

(b)

(c)

Fig. 7. Alumina scale thickness of preoxidized Al-FAs as a function of time: (a) In702 (b) HR224, and (c) APMT.

Oxidation of In702 in ZA produced two distinct alumina zones, with a denser layer formed on top of an internal dispersed phase (Fig. 7a). The dispersed alumina phase formed in In702 (ZA) is thicker than the dense layer. Because the alumina resolved in $\mathrm{XRD}$ is the crystalline polymorphic $\alpha$-corundum phase, which is the most protective structure because it has less crystalline defects, it is hypothesized that the denser alumina layer could protect the alloy from corrosion in molten chlorides. Alumina layers in HR224 are thicker than in APMT alloys (see Figs. 7b and 7c). Aluminum oxides in HR224 are granular and are mixed with $\mathrm{Cr}$ and/or Fe (see Figs. 5a and 5b). This could be the reason why they are thicker than in APMT alloys. Only dense and uniform alumina layers are present in APMT; but they are the thinnest among the AI-FA alloys. 
Figure 8showsthe mass and thickness lossof the pre-oxidized alloys exposed to molten-salt corrosion as a function of immersion time. The maximum thickness loss of $\sim 14 \mu \mathrm{m}$ was obtained for HR224 (ZA and Ar) after $505 \mathrm{~h}$ of exposure. The minimum of 3 $4 \mu \mathrm{m}$ was obtained for $\operatorname{In} 702$ (ZA) for $505 \mathrm{~h}$ of corrosion time.
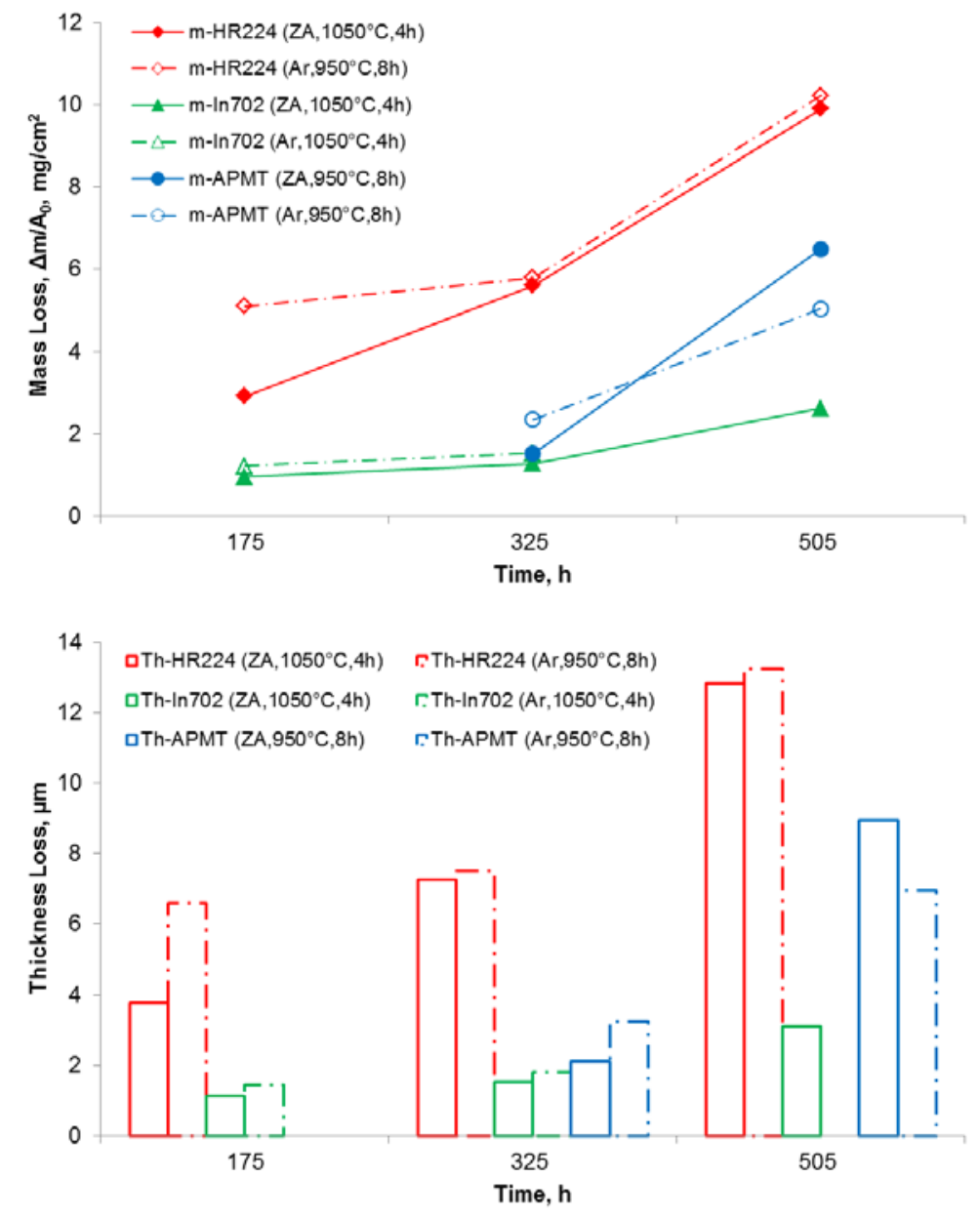

(a)

(b)

Fig. 8. Mass (a) and thickness losses (b) of down-selected pre-oxidized Al-FAs with time during long-term corrosion test in molten eutectic $\mathrm{MgCl}_{2}-64.41 \mathrm{wt} \% \mathrm{KCl}$ at $700^{\circ} \mathrm{C}$ in $\mathrm{Ar}$. Corroded samples were chemically and mechanically cleaned following standard ASTM G1-03.

From the long-term corrosion tests in flowing Ar, it can be seen that HR224 is the worst alloy with the lowest corrosion resistance against molten chlorides. As reported above, its oxides were mixed granular $\mathrm{Al}, \mathrm{Cr}$, and Fe oxides-hence, high mass loss on exposure to chlorides because they are less stable in these environments. The bestperforming alloy is $\operatorname{In} 702$ pre-oxidized in ZA at $1050^{\circ} \mathrm{C}$ during $4 \mathrm{~h}$. This alloy showed denser top alumina layers with dispersed internal alumina zones. This alumina morphology and configuration might have helped bridge the mismatch in coefficient of thermal expansion between the dense top layer and the underlying metallic alloy. This could decrease the rate of spallation (corroborated by lower mass loss in Fig. 8). If the top layer is dense and uniform enough, it could stop ingress of corrosive media toward 
1 the alloy matrix. These hypotheses should be confirmed with further evaluations. None

2 of the Al-FAs reached the expected asymptotic (very small changes with time) corrosion

3 behavior. The pseudo-constant behavior represents the expected passivation of the

4 alloys from the protective behavior of alumina layers.

$5 \quad$ Some samples were corroded during $1000 \mathrm{~h}$ for XRD analyzes of corrosion

6 products. These samples were removed from the salt, rinsed in DI water and analyzed

7 in XRD. The XRD patterns (shown in Fig. 9) were analyzed using

8 UsingX'PertHighScore Plus software. Identified crystalline phases are shown in Fig .9.

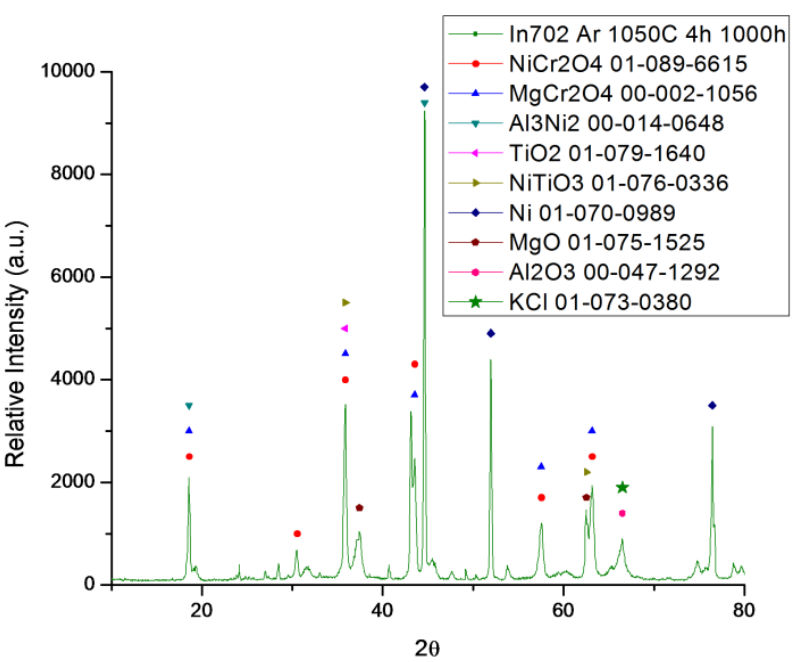

(a)

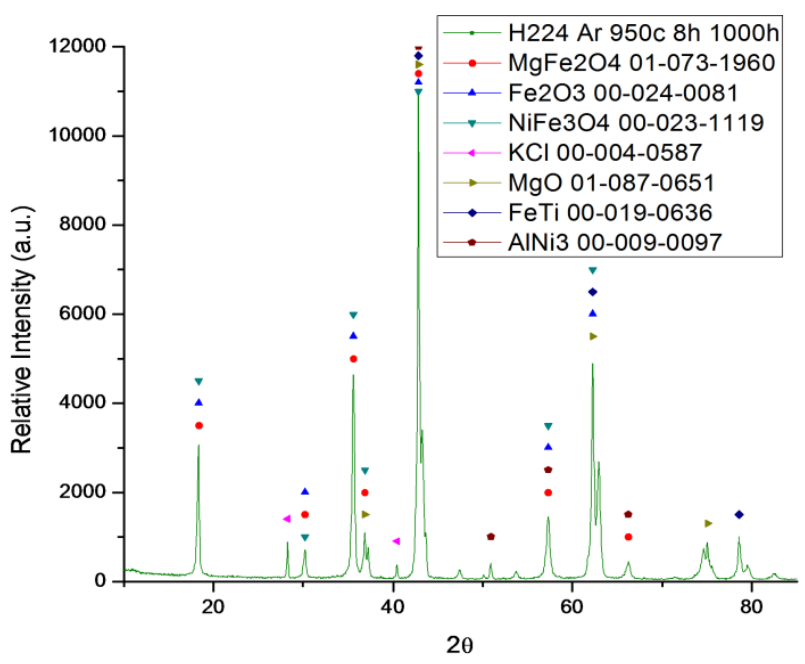

(b)

Fig. 9. XRD patterns with identified phases of (a) In702(Ar) and (b) HR224(Ar) after $1000 \mathrm{~h}$ immersion in molten eutectic $\mathrm{MgCl}_{2}-64.41 \mathrm{wt} \% \mathrm{KCl}$ at $700^{\circ} \mathrm{C}$ in $\mathrm{Ar}$.

Al-FA samples corroded during $505 \mathrm{~h}$ were metallographic characterized to determine distribution of corrosion products across the surface. For this, they were removed from the salt, rinsed in DI water, and encapsulated in bakelite for cross-section analysis. FESEM/EDS micrographs of pre-oxidized and corroded Al-FAs are shown in Figs. 10 - 12. Under isothermal conditions, it appears that alumina scales are stable. It is interesting to see that the oxide scales grew during exposure to molten chlorides, which implies that oxygen permeation occurred into the tube-furnace system used. Thicker alumina layers were obtained for corroded In702 (Ar and ZA) (Fig. 10). Thicknesses were about $50 \mu \mathrm{m}$ and $25 \mu \mathrm{m}$, for In702(Ar) and In702(ZA), respectively. The other alloys presented thinner alumina layers after corrosion. In702 (Fig. 10) and APMT (Fig. 12) showed uniform corrosion, but it appears that HR224 (Fig. 11) has some cracks at the surfaces that could initiate localized corrosion in the future. To determine any change in the corrosion mechanism, longer periods of exposure time will be required. 

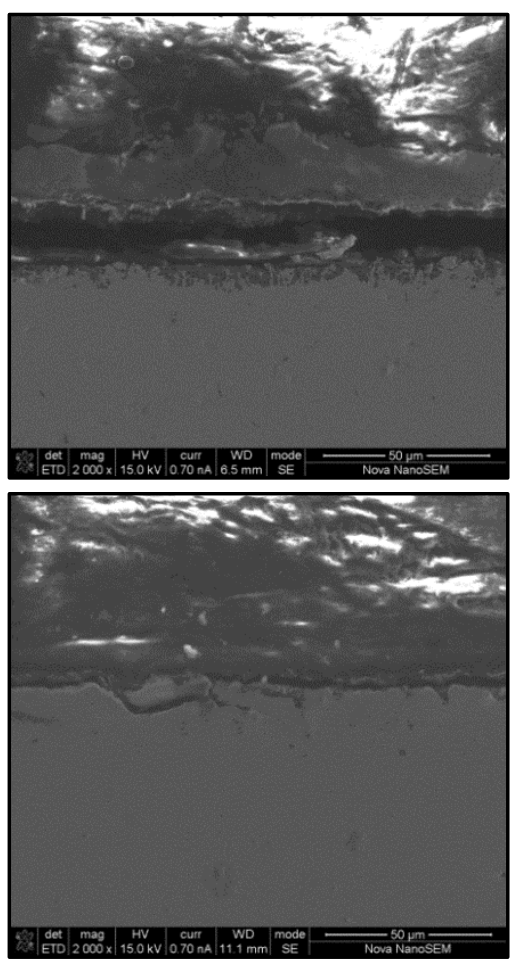
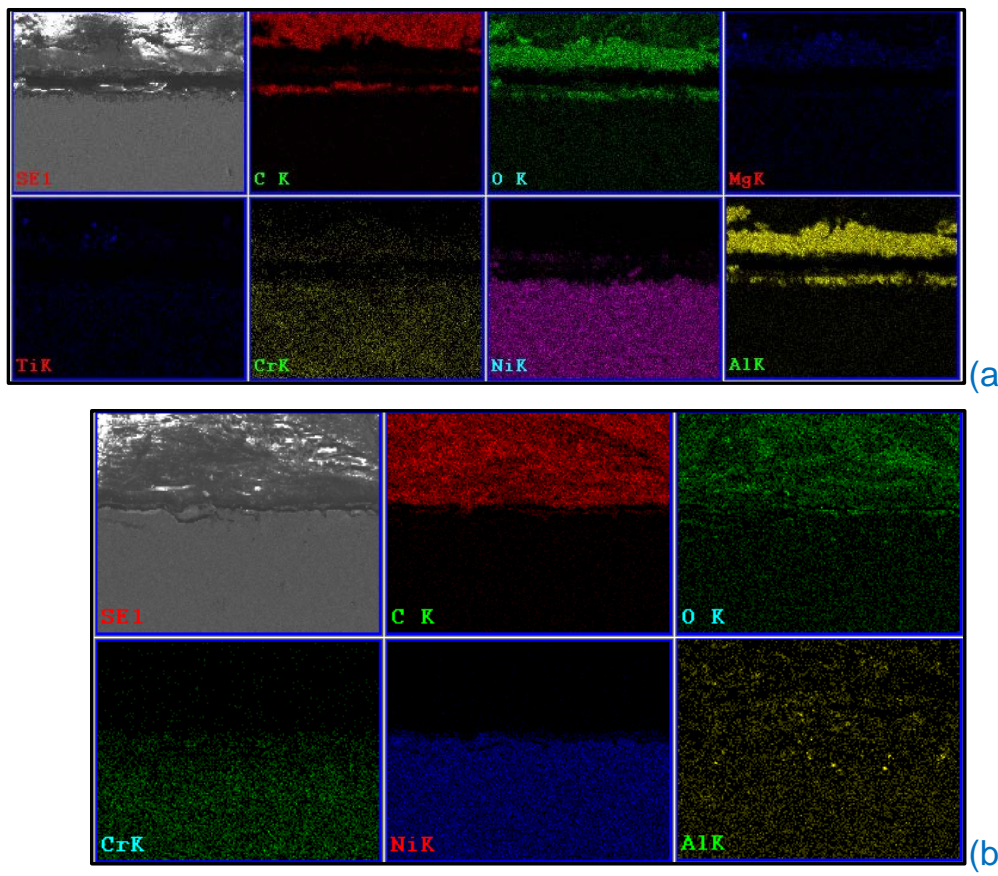

(b)
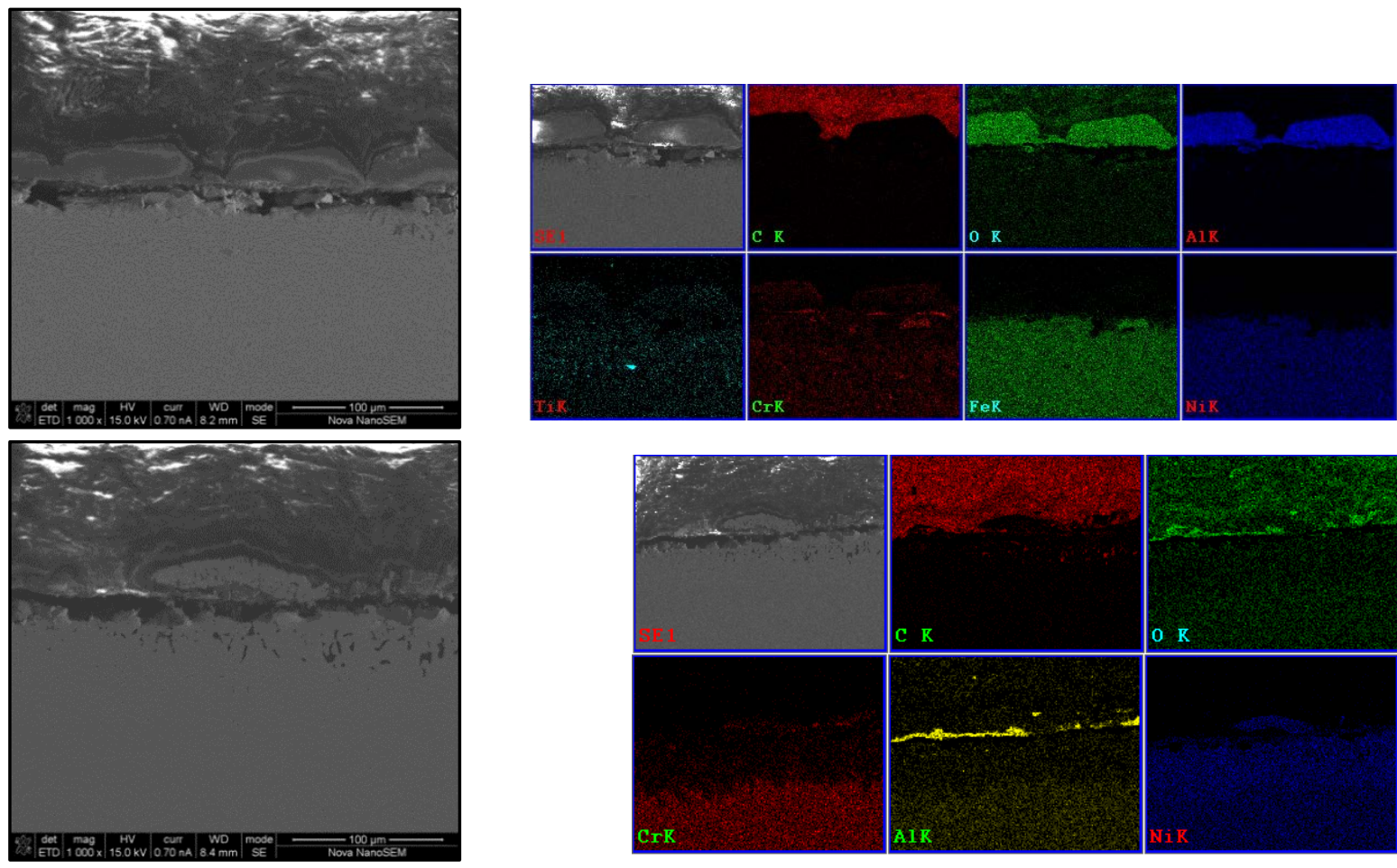

(a)

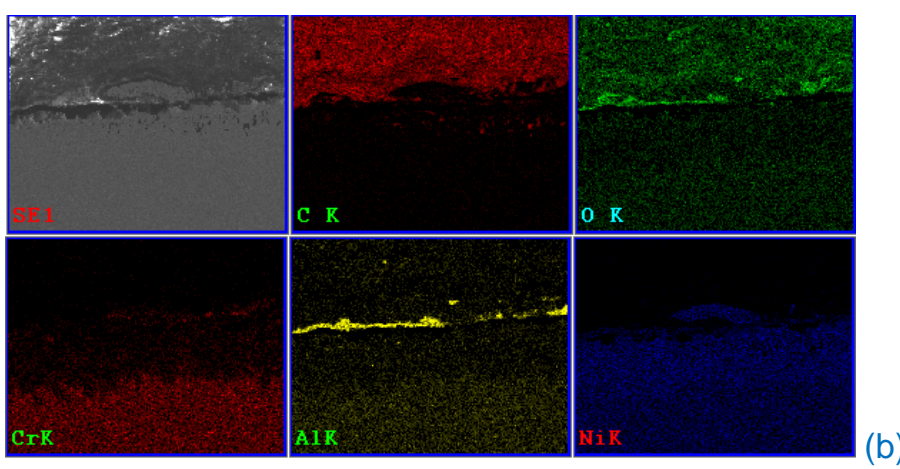

Fig. 11. FESEM micrographs (left) and FESEM/EDS maps (right) of HR224 pre-oxidized and molten chloride corroded at $700^{\circ} \mathrm{C}$ during $505 \mathrm{~h}$ in Ar atmosphere: (a) ZA, $1050^{\circ} \mathrm{C}, 4 \mathrm{~h}$, and (b) $\mathrm{Ar}, 950^{\circ} \mathrm{C}, 8 \mathrm{~h}$. 

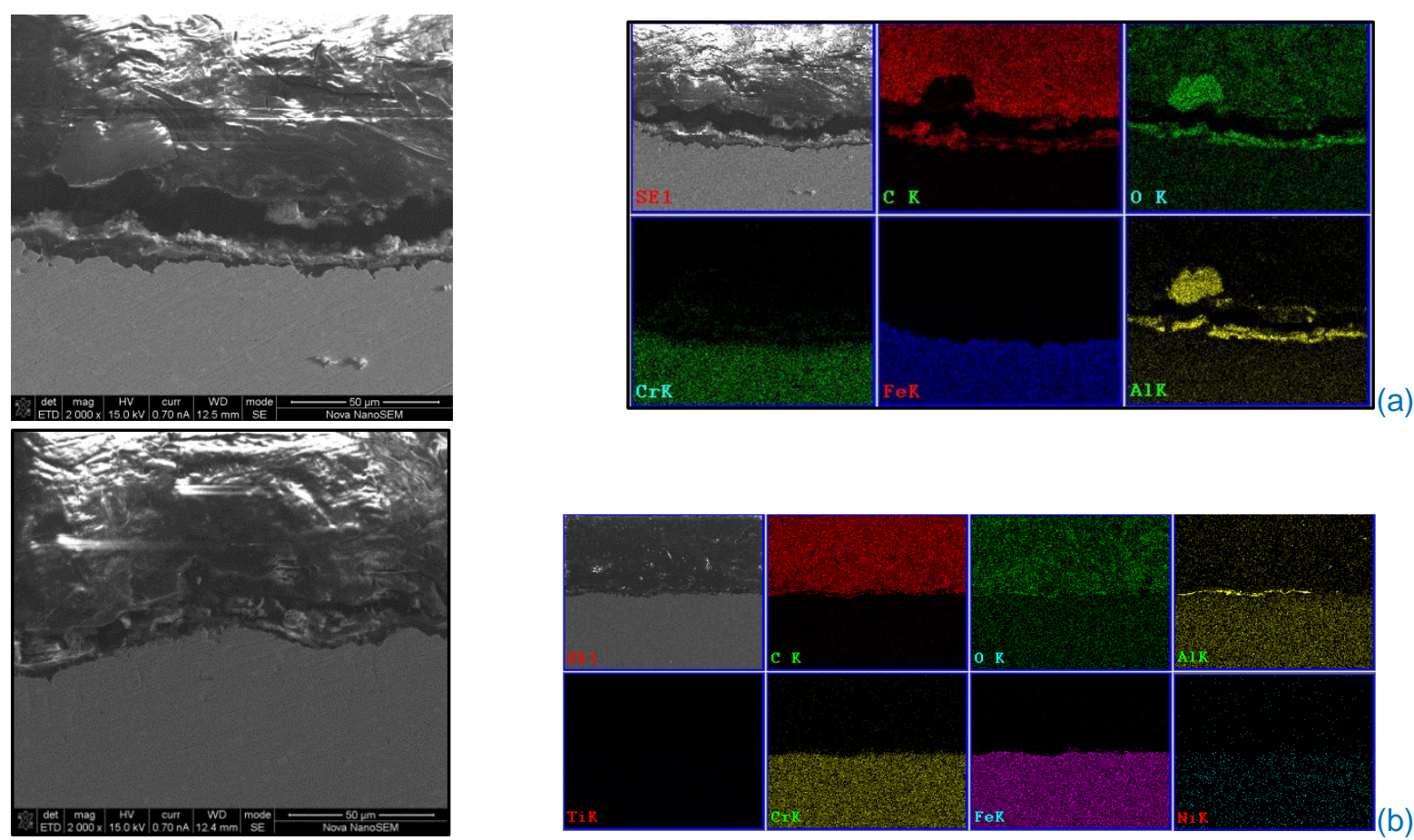

Fig. 12. FESEM micrographs (left) and FESEM/EDS maps (right) of APMT pre-oxidized and molten chloride corroded at $700^{\circ} \mathrm{C}$ during 505 hin Ar atmosphere: (a) ZA, $950^{\circ} \mathrm{C}, 8 \mathrm{~h}$, and (b) Ar, $950^{\circ} \mathrm{C}, 8 \mathrm{~h}$.

The oxidation atmosphere (ZA or Ar) plays an important role in the formation of dense and uniform layers of protective oxides against corrosion in molten chloride. It was noticed that alumina layers formed in Ar atmospheres were in some cases denser but they were in general too thin. Also the low partial pressure of oxygen in $\mathrm{Ar}$ atmospheres did not stop the formation of other Fe-containing oxides. By using ZA atmospheres to pre-oxidize Al-FAs, it is expected that the process will be commercially feasible and cost-effective because regular air can be used instead of controlled inert atmospheres.

The salts collected after each exposure time were analyzed using XRD.Figure 13 shows the XRD patterns and the identified crystalline phases.Aluminum oxides were identified as well as oxides containing Ti, Mo, Ca, Cr and/or Fe. Other chlorides such as $\mathrm{MoCl}_{3}$ and $\mathrm{CrCl}_{3}$ were resolved. $\mathrm{CaFeO}_{4}$ is present in salts from alloys HR224 and AMPT.It is interesting that $\mathrm{MgO}$ was resolved as part of the crystalline phases contained in most of the salts after corrosion. Mg only comes from the $\mathrm{MgCl}_{2}$ of the molten salt, which means that this salt reacts with dissolved oxygen from the environment to form periclaseMgO at high temperatures. 

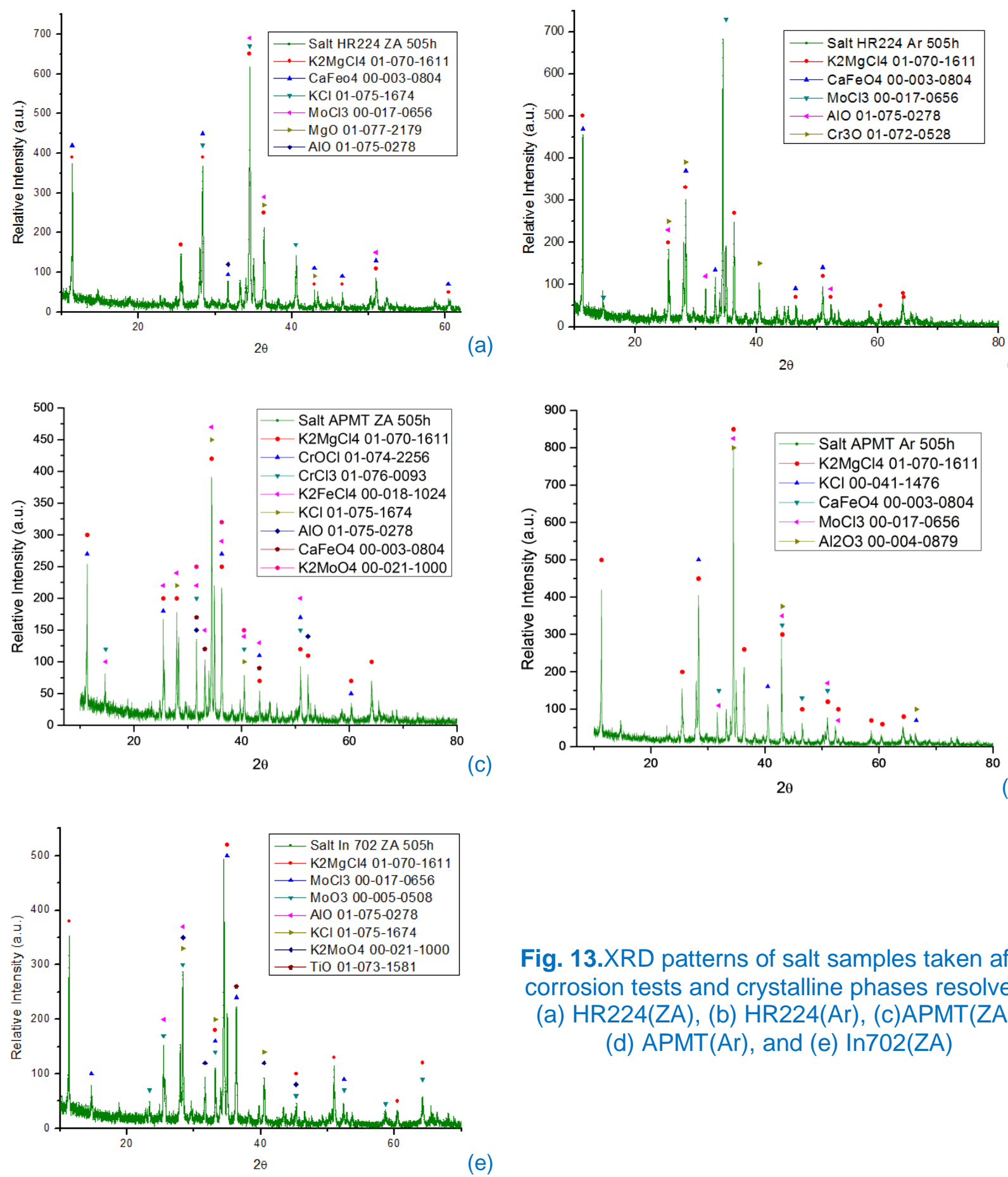

Fig. 13.XRD patterns of salt samples taken after corrosion tests and crystalline phases resolved.

(a) HR224(ZA), (b) HR224(Ar), (c)APMT(ZA),

(d) APMT(Ar), and (e) In702(ZA)

(e)

$1 \quad$ Chemical composition of the salt samples was performed using ICP-MS. Acid

2 digestion was employed to completely dissolve the sample and have all the elements in 3 solution. The composition of salts (see Fig. 14) shows that elements such as $\mathrm{Al}, \mathrm{Cr}, \mathrm{Ni}$, $4 \mathrm{Fe}, \mathrm{Ti}$, and Mo were dissolved from the alloys into the molten salts during corrosion. Ca 5 is an impurity from the salt and $\mathrm{Si}$ is mostly coming from the alloy and the quartz 6 crucible. The highest concentrations were observed for $\mathrm{Cr}$ and Fe. From these data, it 
1 can be concluded that the worst alloys are HR224(ZA) and AMPT(ZA). In general, the 2 best-performing alloy is $\operatorname{In} 702\left(\mathrm{ZA}, 1050^{\circ} \mathrm{C}, 4 \mathrm{~h}\right)$.
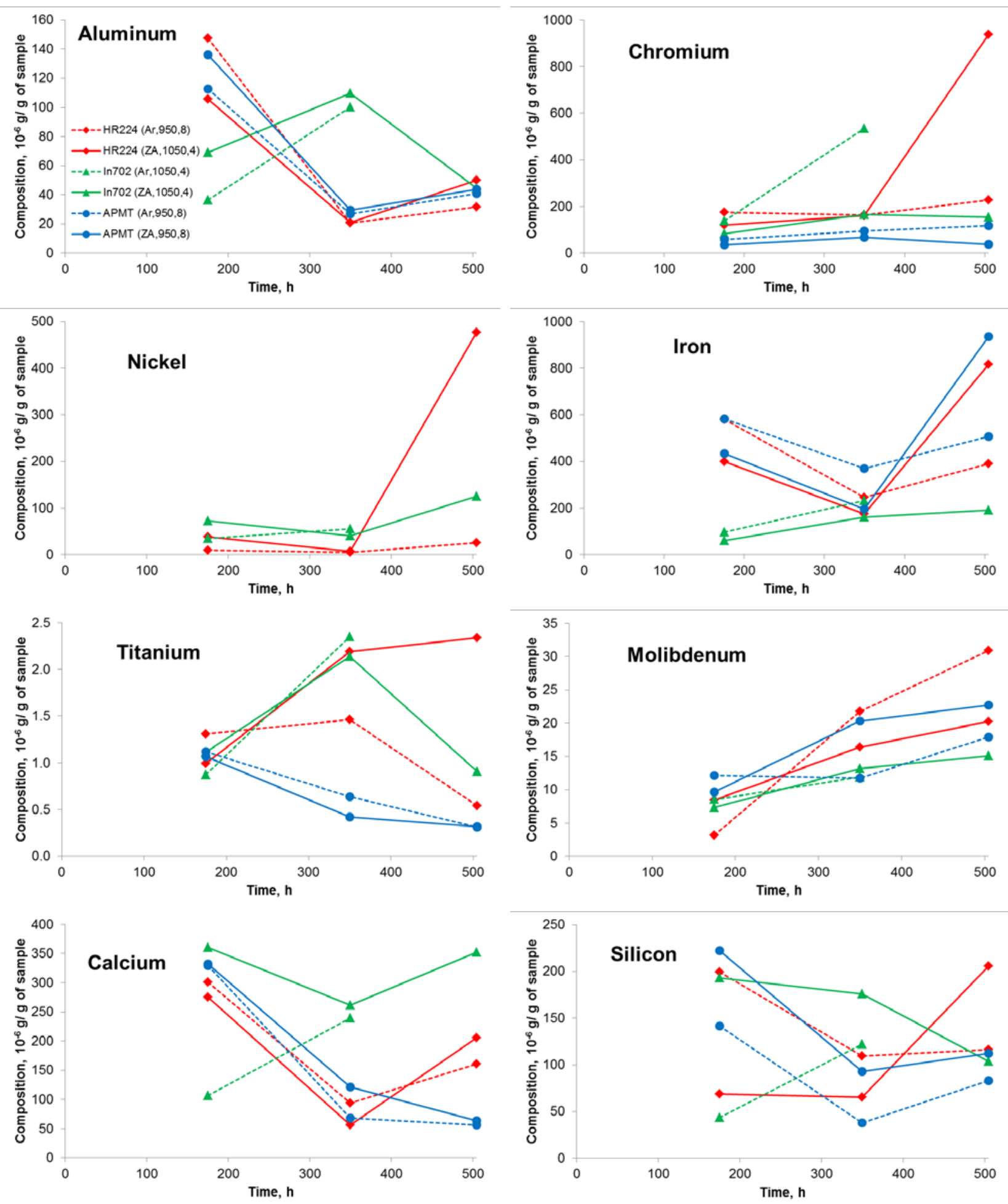

Fig. 14. ICP-MS analyses showing concentration (in ppm) of dissolved elements in molten chloride after corrosion at different immersion times. 
The literature states that formation of metastable alumina polymorphs can lead to crack formation when transforming into stable $\alpha-\mathrm{Al}_{2} \mathrm{O}_{3}$ phase $[13,14]$. To avoid cracking formation due to this solid-solid transformation, protective $\alpha-\mathrm{Al}_{2} \mathrm{O}_{3}$ was produced at the surface of Al-FAs at $1050^{\circ} \mathrm{C}$ in ZA atmospheres. This pre-oxidation treatment already established the presence of the protective layer; so it is believed that if during corrosion this layer spalls off in the salt, the oxygen compounds dissolved into the chloride system will probably allow the reformation of $\alpha-\mathrm{Al}_{2} \mathrm{O}_{3}$, even at low temperatures because of the presence of $\alpha-\mathrm{Al}_{2} \mathrm{O}_{3}$ at the surface that will serve as nucleants of new crystals.

To allow the reformation of alumina certain amount of dissolved oxygen must be present in the molten salt. To maintain a certain level of oxygen-dissolved compounds in the salt, it is recommended to evaluate the effect of oxygen-containing gases bubbled into the molten salt. This evaluation should focus on corrosion mitigation of Al-FAs by determining if the regeneration of protective $\alpha-\mathrm{Al}_{2} \mathrm{O}_{3}$ is feasible. To stabilize the alumina layers during corrosion in molten salts, it is suggested to use an atmosphere with a higher oxidation potential, which could move the alloy's potential to a passivation region in which the aluminum oxide at the surface could remain stable and protective.

\section{Conclusions}

Long-term weight-change corrosion tests up to $505 \mathrm{~h}$ and electrochemical techniques were employed to study the corrosion of alumina-forming alloys (Al-FAs) in molten chlorides in flowing Ar atmospheres. Corrosion tests showed that the bestperforming alloy resulted in In702 pre-oxidized in $\mathrm{ZA}$ at $1050^{\circ} \mathrm{C}$ during $4 \mathrm{~h}$ due to the presence of more stable alumina layers. XRD, ICP-MS, and FESEM/EDS of Al-FAs demonstrated that high Ni content might decrease the corrosion of alloys in molten chlorides. From ICP-MS analysis, $\mathrm{Cr}$ and $\mathrm{Fe}$ are highly corroded from the alloys into the molten salts, followed by $\mathrm{Al}, \mathrm{Ni}$, and then $\mathrm{Mo}$.

XRD patterns resolved the formation of several oxides as corrosion products, which confirms that a certain amount of oxygen permeated during the corrosion tests. It is believed that this amount of permeated oxygen, dissolved into the molten chloride, was not enough to stabilize and reform alumina layers.

To determine if alumina scales can re-heal and be stable, future testing will be performed under thermal cycling in an oxygen-containing atmosphere. These conditions are found in CSP applications and the stability of the protective oxides must be verified.

\section{Acknowledgment}

The work at NREL was supported financially by the U.S. Department of Energy under Contract No. DE-AC36-08-GO28308.

\section{Nomenclature}

CSP concentrating solar power 
1 HTF heat transfer fluid

2 TES thermal energy storage

3 Al-FA alumina-forming alloy

4 References

1. K. Vignarooban, X. Xu, A. Arvay, K. Hsu, and A.M. Kannan, Heat transfer fluids for concentrating solar power systems - A review, Applied Energy146 (2015) 383-396.

2. V. Ignatiev and A. Surenkov, "Chapter 5: Corrosion phenomena induced by molten salts in Generation IV nuclear reactors" Structural Materials for Generation IV Nuclear Reactors, Elsevier Ltd. (2017): 153 - 189.

3. K. Sridharan and T.R. Allen, "Chapter 12: Corrosion in Molten Salts," Molten Salts Chemistry, Elsevier Inc. (2013): $241-267$.

4. M. Groll, O. Brost, and D. Heine, Corrosion of steels in contact with salt eutectics as latent heat storage materials: Influence of water and other impurities, Heat Recovery Systems \& CHP10 (1990) 567-572.

5. C. Cuevas-Arteaga, J. Uruchurtu-Chavarin, J. Porcayo-Calderon, G. IzquierdoMontalvo, and J. Gonzalez, Study of molten salt corrosion of HK-40m alloy applying linear polarization resistance and conventional weight loss techniques, Corrosion Science 46 (2004) 2663-2679.

6. J. Porcayo-Calderon, O. Sotelo-Mazon, V.M. Salinas-Bravo, C.D. Arrieta-Gonzalez, J.J. Ramos-Hernandez, and C. Cuevas-Arteaga, Electrochemical performance of $\mathrm{Ni20Cr}$ coatings applied by combustion powder spray in $\mathrm{ZnCl}_{2}-\mathrm{KCl}$ molten salts, Int. J. Electrochem. Sci.7 (2012) 1134-1148.

7. Y.S. Li, M. Spiegel, and S. Shimad, Corrosion behaviour of various model alloys with $\mathrm{NaCl}-\mathrm{KCl}$ coating, Materials Chemistry and Physics, 93 (2005) 217-223.

8. Y. Yamamoto, M.P. Brady, M.L. Santella, H. Bei, P.J. Maziasz, and B.A. Pint, Development of alumina-forming austenitic stainless steels, $33^{\text {rd }}$ International Technical Conference on Coal Utilization \& Fuel Systems, Clearwater, FL June 1-5, 2008.

9. Y.S. Li. Internal Oxidation of $\mathrm{Fe}-\mathrm{Al}$ alloys in a $\mathrm{KCl}$-air atmosphere at $650^{\circ} \mathrm{C}$. Oxid. Met. 61(3/4) (2004) 303-322. 
10. J.C. Gomez-Vidal and R. Tirawat, Corrosion of alloys in a chloride molten salt ( $\mathrm{NaCl}-\mathrm{LiCl})$ for solar thermal technologies, Solar Energy Materials \& Solar Cells157 (2016) 234-244.

11. M.P. Brady J. Magee, Y. Yamamoto, D. Helmick, and L. Wang. Co-optimization of wrought alumina-forming austenitic stainless steel composition ranges for hightemperature creep and oxidation/corrosion resistance, Materials Science \& Engineering A590 (2014) 01-115.

12. K. Hellstroom, J. Hall, P. Malmberg, Y. Cao, M. Norell, and J.-E. Svensson. Mitigation of fireside corrosion in power plants: The combined effect of sulfur dioxide and potassium chloride on the corrosion of a FeCrAl alloy. Energy Fuels, 28 (2014) 6116-6129.

13. S. Kitaoka, T. Kuroyam, M. Matsumoto, R. Kitazawa, and Y. Kagawa. Control of polymorphism in $\mathrm{Al}_{2} \mathrm{O}_{3}$ scale formed by oxidation of alumina-forming alloys. Corrosion Science52 (2010) 429-434.

14. T. Sudiro, T. Sano, S. Kyo, O. Ishibashi, M. Nakamori, and K. Kurokawa. A comparative study of high temperature corrosion of $\mathrm{Al}_{2} \mathrm{O}_{3}, \mathrm{SiO}_{2}$ and $\mathrm{Al}_{2} \mathrm{O}_{3}-\mathrm{SiO}_{2}$ forming alloys in a $\mathrm{Na}_{2} \mathrm{SO}_{4}-\mathrm{NaCl}$ atmosphere. Oxid. Met. 80 (2013) 589-597.

15. M. Matsumoto, K. Hayakawa, S. Kitaoka, H. Matsubara, H. Takayama, Y. Kagiya, and $\mathrm{Y}$. Sugita. The effect of preoxidation atmosphere on oxidation behavior and thermal cyclic life of thermal barrier coatings, Mater. Sci. Eng. A 411 (2006) 119125.

16. M. Matsumoto, T. Kato, K. Hayakawa, N. Yamaguchi, S. Kitaoka, and H. Matsubara. The effect of pre-oxidation atmosphere on the durability of EB-PVD thermal barrier coatings with CoNiCrAlY bond coats, Surf. Coat. Technol. 202 (2008) 2742-2748.

17. A. Pint, M. Treska, and L.W. Hobbs. The effect of various oxide dispersions on the phase compositing and morphology of $\mathrm{Al}_{2} \mathrm{O}_{3}$ scales grown on $\beta$-NiAl, Oxid. Met. 47 (1997) 1-20.

18.X. Peng, D.R. Clarke, and F. Wang. Transient-alumina transformations during the oxidation of magnetron-sputtered CoCrAlnanocrystalline, Oxid. Met. 60 (2003) 225240. 
19. R. Eriksson, K. Yuan, X. Li, and R. Peng. MCrAlY coating design based on oxidation-diffusion modeling. Part II: Lifing aspects, Surface and Coatings Technology253 (2014) 27-37.

20. M.P. Brady, J. L. Smialek, J. Smiths, and D.L. Humphreys. The role of $\mathrm{Cr}$ in promoting protective alumina scale formation by $\mathrm{Y}$-based Ti-Al-Cr alloys - I. Compatibility with alumina and oxidation behavior in oxygen. Acta Mater.45 (1997) 2357-2369.

21. B. Jönsson, Q. Lu, D. Chandrasekaran, R. Berglund, and F. Rave. Oxidation and creep limited lifetime of Kanthal APMT, a dispersion strengthened FeCrAIMo alloy designed for strength and oxidation resistance at high temperatures. Oxid. Met. 79 (2013) 29-39.

22. M.A. Espinosa-Medina, M. Casales, A. Martinez-Villafañe, J. Porcayo-Calderon, L. Martinez, and J.G. Gonzalez-Rodriguez, Hot corrosion of atomized iron aluminides doped with boron and reinforced with alumina, Materials Science and EngineeringA300 (2001) 183-189.

23. J. Cai, B. Xu, and G. Ling, Observation on the interface of $\alpha-\mathrm{Al}_{2} \mathrm{O}_{3} / \mathrm{Cr}_{2} \mathrm{O}_{3}$ : Prepared by oxidation of $\mathrm{Al}_{45} \mathrm{Cr}_{7}$, Applied Surface Science 268 (2013) 111-116.

24. M.A. Espinosa-Medina, G. Carbajal-De la Torre, H.B. Liu, A. Martínez-Villafañe, and J.G. González-Rodriguez, Hot corrosion behaviour of Fe-Al based intermetallic in molten $\mathrm{NaVO}_{3}$ salt, Corrosion Science51 (2009) 1420-1427.

25. J.G. Gonzalez-Rodriguez, E. Mejia, M.A. Lucio-Garcia, V.M. Salinas-Bravo, J. Porcayo-Calderon, and A. Martinez-Villafañe, An electrochemical study of the effect of $\mathrm{Li}$ on the corrosion behavior of $\mathrm{Ni}_{3} \mathrm{Al}$ intermetallic alloy in molten $(\mathrm{Li}+\mathrm{K})$ carbonate, Corrosion Science51 (2009) 1619-1627.

26. S. Frangini, F. Zaza, and A. Masci, Molten carbonate corrosion of a 13-Cr ferritic stainless steel protected by a perovskite conversion treatment: Relationship with the coating microstructure and formation mechanism, Corrosion Science62 (2012) 136146.

27.R.A. Rapp and Y.S. Zhang, Hot corrosion of materials: Fundamental studies, Journal of Metals46 (1994) 47-55. 
1 28. M. F. Morks, I. Cole, P. Corrigan, and A. Kobayashi. Electrochemical

2 characterization of plasma sprayed alumina coatings. Journal of Surface Engineered

$3 \quad$ Materials and Advanced Technology1 (2011) 107-111.

4 29. J.C. Gomez-Vidal and E. Morton, Castable cements to prevent corrosion of metals in

5 molten salts. Solar Energy Materials \& Solar Cells153 (2016) 44-51.

6 30.G.Y. Lai, High-Temperature Corrosion and Materials Applications, ASM

7 International, (2007): 10 - 19.

8 


\section{Tables' captions}

2 Table 1.Candidate alumina-forming alloys chemical composition and mechanical properties. UTS: ultimate tensile strength; YS: yield strength.

4 Table 2.Test matrix for pre-oxidation conditions. 
$1 \quad$ Table 1.

\begin{tabular}{cccccccccc}
\hline & \multicolumn{4}{c}{ Composition, wt\% } & \multicolumn{3}{c}{ Mechanical Properties, MPa } \\
\cline { 2 - 9 } Alloy & $\mathbf{N i}$ & $\mathbf{C r}$ & Al & Fe & Other & \multicolumn{2}{c}{$\begin{array}{c}\text { UTS } \\
\left(\mathbf{T},{ }^{\circ} \mathbf{C}\right)\end{array}$} & $\begin{array}{c}\mathbf{2 \%}_{\text {offset }} \text { YS } \\
\left(\mathbf{T},{ }^{\circ} \mathbf{C}\right)\end{array}$ \\
\hline $\begin{array}{c}\text { Haynes } \\
224\end{array}$ & $\begin{array}{c}46 . \\
4\end{array}$ & 20.5 & 3.2 & 27.6 & $\begin{array}{c}0.2 \mathrm{Mo}, 0.3 \mathrm{Mn}, \\
0.3 \mathrm{Si}, 0.4 \mathrm{Ti}, 0.4 \mathrm{Co}\end{array}$ & $\begin{array}{c}575 \\
(650)\end{array}$ & $\begin{array}{c}499 \\
(760)\end{array}$ & $\begin{array}{c}398 \\
(650)\end{array}$ & $\begin{array}{c}420 \\
(760)\end{array}$ \\
\hline $\begin{array}{c}\text { Kanthal } \\
\text { APMT }\end{array}$ & - & 21 & 5 & $\sim 70$ & $3 \mathrm{Mo}$ & $\begin{array}{c}420 \\
(600)\end{array}$ & $\begin{array}{c}120^{*} \\
(800)\end{array}$ & - \\
\hline $\begin{array}{c}\text { Inconel } \\
702\end{array}$ & -75 & $\begin{array}{c}14- \\
17\end{array}$ & $\begin{array}{c}2.75- \\
3.75\end{array}$ & 2 & $\begin{array}{c}0.2 \mathrm{Mo}, 0.7 \mathrm{Mn}, \\
0.7 \mathrm{Ti}\end{array}$ & $\begin{array}{c}620 \\
(650)\end{array}$ & $\begin{array}{c}550 \\
(760)\end{array}$ & $\begin{array}{c}550 \\
(650)\end{array}$ & $\begin{array}{c}482 \\
(760)\end{array}$ \\
\hline
\end{tabular}

2 *: No data are available at $760^{\circ} \mathrm{C}$ for comparison with the other alloys. The maximum CSP operating temperature is 3 expected to be around $730^{\circ} \mathrm{C}$.

4 Note: Alloys were selected based on similar UTS and YS values to those of other high-strength alloys. These alloys $5 \quad$ are usually Ni-superalloys, Incoloy $800 \mathrm{H}$, and high-stainless steel. 
$1 \quad$ Table 2.

\begin{tabular}{cccccc}
\hline & & \multicolumn{4}{c}{ Conditions: $\mathbf{T}\left({ }^{\circ} \mathbf{C}\right), \mathbf{t}(\mathbf{h})$} \\
Atmosphere & Alloy & $\mathbf{1}$ & $\mathbf{2}$ & $\mathbf{3}$ & $\mathbf{4}$ \\
\hline \multirow{2}{*}{ Zero Air $\left(80 \% \mathrm{~N}_{2}\right.}$, & HR224 & 1050,4 & 950,8 & 950,20 & \\
$\left.20 \% \mathrm{O}_{2}\right)$ & APMT & 1050,8 & 950,8 & 950,20 & \\
& In702 & 1050,4 & 1050,8 & 950,8 & 950,20 \\
\hline \multirow{3}{*}{ Pure Ar $(99.9999 \%)$} & HR224 & 1050,4 & 950,8 & 950,20 & \\
& APMT & 1050,8 & 950,8 & 950,20 & \\
& In702 & 1050,4 & 1050,8 & 950,8 & 950,20 \\
\hline
\end{tabular}

2 


\section{Figure captions}

Fig. 1.XRD patterns and identified phases of In702 bare and oxidized in zero air (ZA) and argon (Ar).

Fig. 2.XRD patterns and identified phases of HR224 bare and oxidized in zero air (ZA) and $\operatorname{argon}(\mathrm{Ar})$.

Fig. 3.XRD patterns and identified phases of Kanthal APMT oxidized in zero air (ZA) and argon (Ar).

Fig. 4.Down-selected pre-oxidized In702. Left: FESEM-BSE micrograph, right: EDS maps: (a) (ZA, $\left.1050^{\circ} \mathrm{C}, 4 \mathrm{~h}\right)$, (b) $\left(\mathrm{Ar}, 1050^{\circ} \mathrm{C}, 4 \mathrm{~h}\right)$.

Fig. 5. Down-selected pre-oxidized HR224. Left: FESEM-BSE micrograph, right: EDS maps: (a) (ZA, $\left.1050^{\circ} \mathrm{C}, 4 \mathrm{~h}\right),(\mathrm{b})\left(\mathrm{Ar}, 950^{\circ} \mathrm{C}, 8 \mathrm{~h}\right)$.

Fig. 6. Down-selected pre-oxidized APMT. Left: FESEM-BSE micrograph, right: EDS maps: (a) (ZA, $\left.950^{\circ} \mathrm{C}, 8 \mathrm{~h}\right),(\mathrm{b})\left(\mathrm{Ar}, 950^{\circ} \mathrm{C}, 8 \mathrm{~h}\right)$.

Fig. 7. Alumina scale thickness of pre-oxidized Al-FAs as a function of time: (a) $\ln 702$ (b) HR224, and (c) APMT.

Fig. 8. Mass (a) and thickness losses (b) of down-selected pre-oxidized Al-FAs with time during long-term corrosion test in molten eutectic $\mathrm{MgCl}_{2}-64.41 \mathrm{wt} \% \mathrm{KCl}$ at $700^{\circ} \mathrm{C}$ in $\mathrm{Ar}$. Corroded samples were chemically and mechanically cleaned following standard ASTM G1-03.

Fig. 9. XRD patterns with identified phases of (a) In702(Ar) and (b) HR224(Ar) after $1000 \mathrm{~h}$ immersion in molten eutectic $\mathrm{MgCl} 2-64.41 \mathrm{wt} \% \mathrm{KCl}$ at $700^{\circ} \mathrm{C}$ in $\mathrm{Ar}$.

Fig. 10. FESEM micrographs (left) and FESEM/EDS maps (right) of In702 pre-oxidized and molten chloride corroded at $700^{\circ} \mathrm{C}$ during $505 \mathrm{~h}$ in Ar atmosphere: (a) ZA, $1050^{\circ} \mathrm{C}, 4 \mathrm{~h}$, and (b) $\mathrm{Ar}, 1050^{\circ} \mathrm{C}, 4 \mathrm{~h}$.

Fig. 11. FESEM micrographs (left) and FESEM/EDS maps (right) of HR224 pre-oxidized and molten chloride corroded at $700^{\circ} \mathrm{C}$ during $505 \mathrm{~h}$ in Ar atmosphere: (a) ZA, $1050^{\circ} \mathrm{C}, 4 \mathrm{~h}$, and (b) $\mathrm{Ar}, 950^{\circ} \mathrm{C}, 8 \mathrm{~h}$.

Fig. 12. FESEM micrographs (left) and FESEM/EDS maps (right) of APMT pre-oxidized and molten chloride corroded at $700^{\circ} \mathrm{C}$ during $505 \mathrm{~h}$ in Ar atmosphere: (a) ZA, $950^{\circ} \mathrm{C}, 8 \mathrm{~h}$, and (b) $\mathrm{Ar}, 950^{\circ} \mathrm{C}, 8 \mathrm{~h}$.

Fig. 13. XRD patterns of salt samples taken after corrosion tests and crystalline phases resolved. (a) HR224(ZA), (b) HR224(Ar), (c)APMT(ZA), (d) APMT(Ar), and (e) In702(ZA).

Fig. 14. ICP-MS analyses showing concentration (in ppm) of dissolved elements in molten chloride after corrosion at different immersion times. 
Fig. 1.

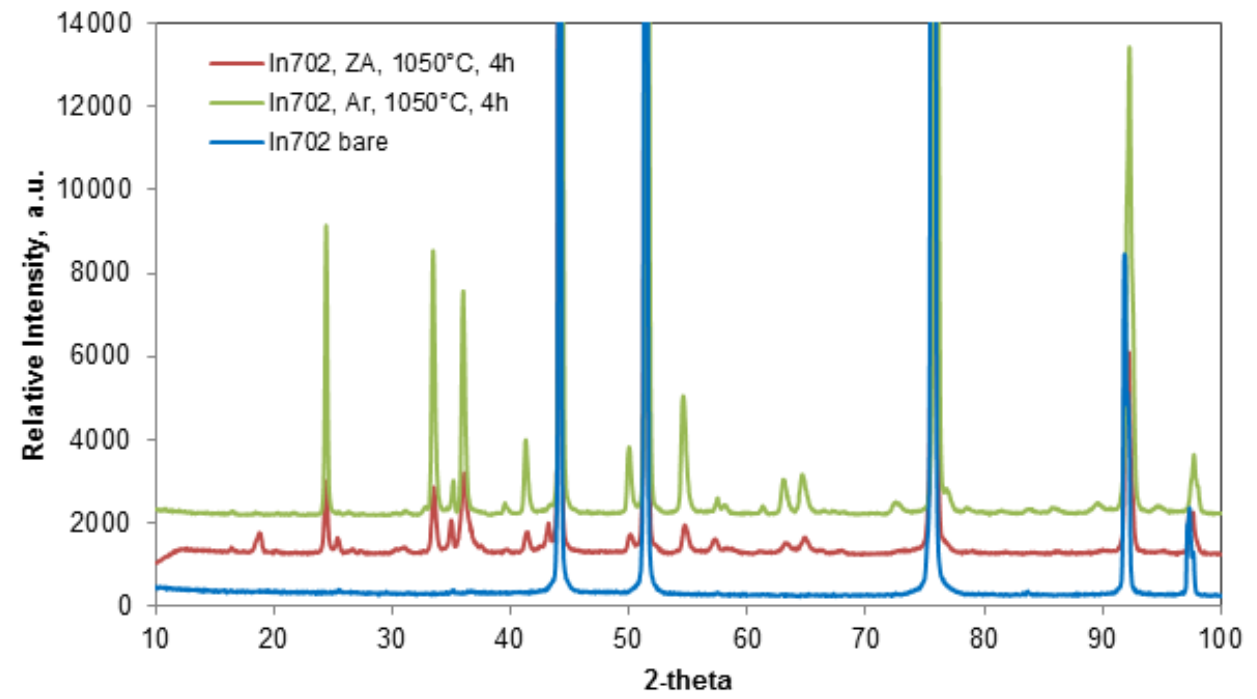

2

\begin{tabular}{ccll}
\hline Sample & Ref. Code & \multicolumn{1}{c}{ Compound Name } & Chemical Formula \\
\hline In702 bare & $00-033-0945$ & austenitic steel & $\mathrm{Ni}_{2.9} \mathrm{Cr}_{0.7} \mathrm{Fe}_{0.36}$ \\
& $03-065-5559$ & Chromium Nickel & $\mathrm{Cr}_{1.12} \mathrm{Ni}_{2.88}$ \\
\hline \multirow{2}{*}{ In702, ZA, } & $00-035-1112$ & Chromium Iron Oxide & $\mathrm{Cr}_{1.3} \mathrm{Fe}_{0.7} \mathrm{O}_{3}$ \\
$1050^{\circ} \mathrm{C}, 4 \mathrm{~h}$ & $00-051-1394$ & Corundum - Aluminum Chromium Oxide & $\alpha-\left(\mathrm{Al}_{0.9} \mathrm{Cr}_{0.1}\right)_{2} \mathrm{O}_{3}$ \\
& $01-085-1828$ & Hercynite & $\mathrm{Al}_{2} \mathrm{Fe} \mathrm{O}_{4}$ \\
\hline In702, Ar, & $01-084-0311$ & Iron Oxide & $\mathrm{Fe}_{2} \mathrm{O}_{3}$ \\
$1050^{\circ} \mathrm{C}, 4 \mathrm{~h}$ & $00-046-1212$ & Corundum & $\mathrm{\alpha}-\mathrm{Al}_{2} \mathrm{O}_{3}$ \\
\hline
\end{tabular}

3

4 
Fig. 2.

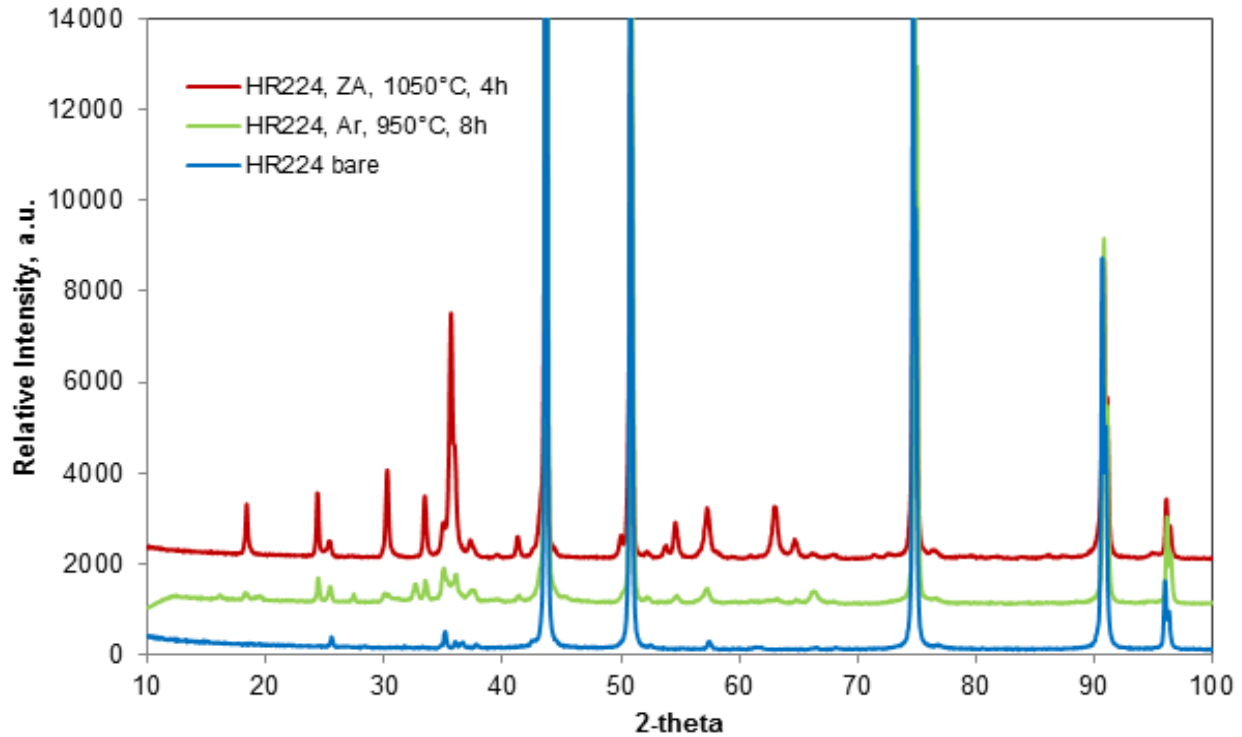

\begin{tabular}{ccll}
\hline Sample & Ref. Code & \multicolumn{1}{c}{ Compound Name } & \multicolumn{1}{c}{ Chemical Formula } \\
\hline \multirow{2}{*}{ HR224 bare } & $00-047-1405$ & Iron Nickel & $\mathrm{Fe}_{0.64} \mathrm{Ni}_{0.36}$ \\
& $00-003-1209$ & Iron Nickel & $\mathrm{Fe} \mathrm{Ni}$ \\
\hline & $01-074-2081$ & Nickel Iron Oxide & $\mathrm{Ni} \mathrm{Fe}_{2} \mathrm{O}_{4}$ \\
$\mathrm{HR} 224, \mathrm{ZA}$, & $01-075-0782$ & Corundum & $\mathrm{\alpha}-\mathrm{Al}_{2} \mathrm{O}_{3}$ \\
$1050^{\circ} \mathrm{C}, 4 \mathrm{~h}$ & $01-084-0311$ & Hematite & $\mathrm{Fe}_{2} \mathrm{O}_{3}$ \\
& $01-082-1484$ & Chromium Oxide & $\mathrm{Cr}_{2} \mathrm{O}_{3}$ \\
& $01-089-3855$ & Iron Chromate & $\mathrm{Fe} \mathrm{Cr}_{2} \mathrm{O}_{4}$ \\
\hline HR224, Ar, & $00-049-1657$ & Aluminum Iron Oxide & $\mathrm{Al}_{3} \mathrm{Fe}_{5} \mathrm{O}_{12}$ \\
$950^{\circ} \mathrm{C}, 8 \mathrm{~h}$ & $00-051-1394$ & Corundum - Aluminum Chromium Oxide & $\alpha-\left(\mathrm{Al}_{0.9} \mathrm{Cr}_{0.1}\right)_{2} \mathrm{O}_{3}$ \\
\hline
\end{tabular}


Fig. 3.

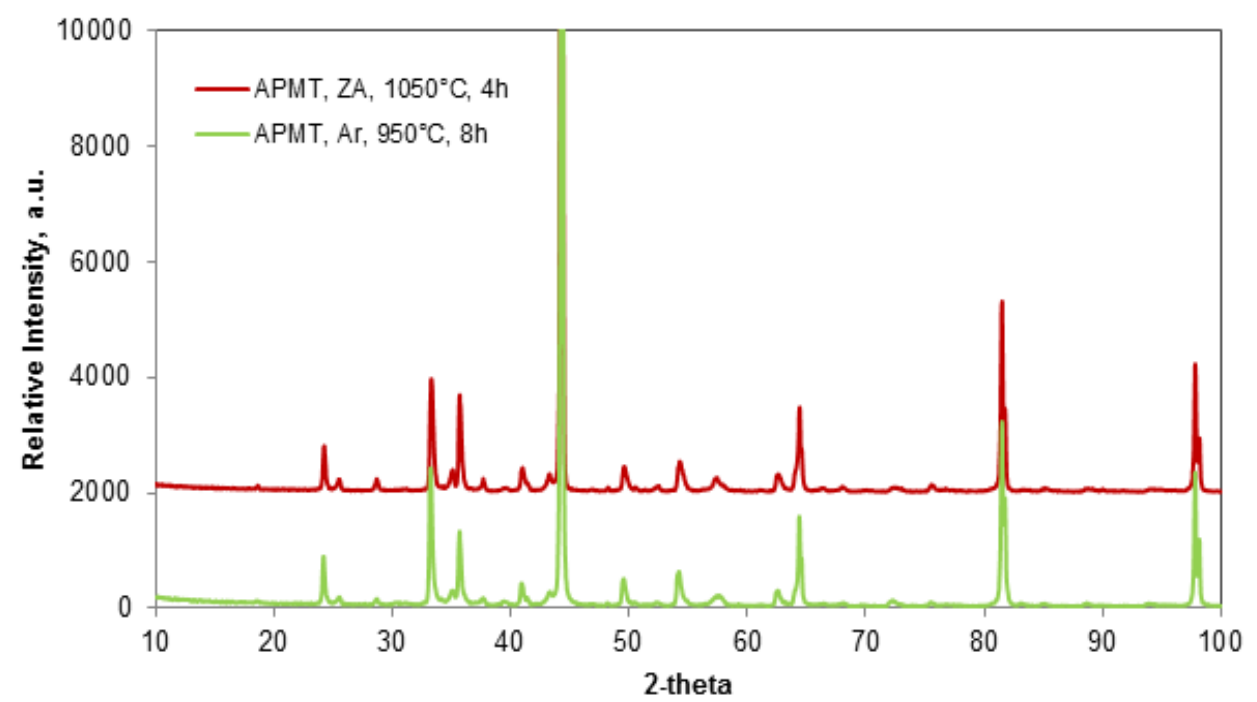

2

\begin{tabular}{ccll}
\hline Sample & Ref. Code & \multicolumn{1}{c}{ Compound Name } & Chemical Formula \\
\hline \multirow{2}{*}{ Substrate } & $01-085-1410$ & Iron & $\mathrm{Fe}$ \\
& $00-045-0982$ & Aluminum Iron & $\mathrm{Al}_{0.4} \mathrm{Fe}_{0.6}$ \\
\hline APMT, ZA, & $01-089-0599$ & Hematite & $\mathrm{Fe}_{2} \mathrm{O}_{3}$ \\
$1050^{\circ} \mathrm{C}, 4 \mathrm{~h}$ & $01-071-0958$ & Corundum - Aluminum Chromium Oxide & $\left(\mathrm{Al}_{0.948} \mathrm{Cr}_{0.052}\right)_{2} \mathrm{O}_{3}$ \\
\hline APMT, $\mathrm{Ar}$, & $01-089-0596$ & Hematite & $\mathrm{Fe}_{2} \mathrm{O}_{3}$ \\
$950^{\circ} \mathrm{C}, 8 \mathrm{~h}$ & $00-051-1394$ & Corundum - Aluminum Chromium Oxide & $\left(\mathrm{Al}_{0.9} \mathrm{Cr}_{0.1}\right)_{2} \mathrm{O}_{3}$ \\
\hline
\end{tabular}

3 
$1 \quad$ Fig. 4.
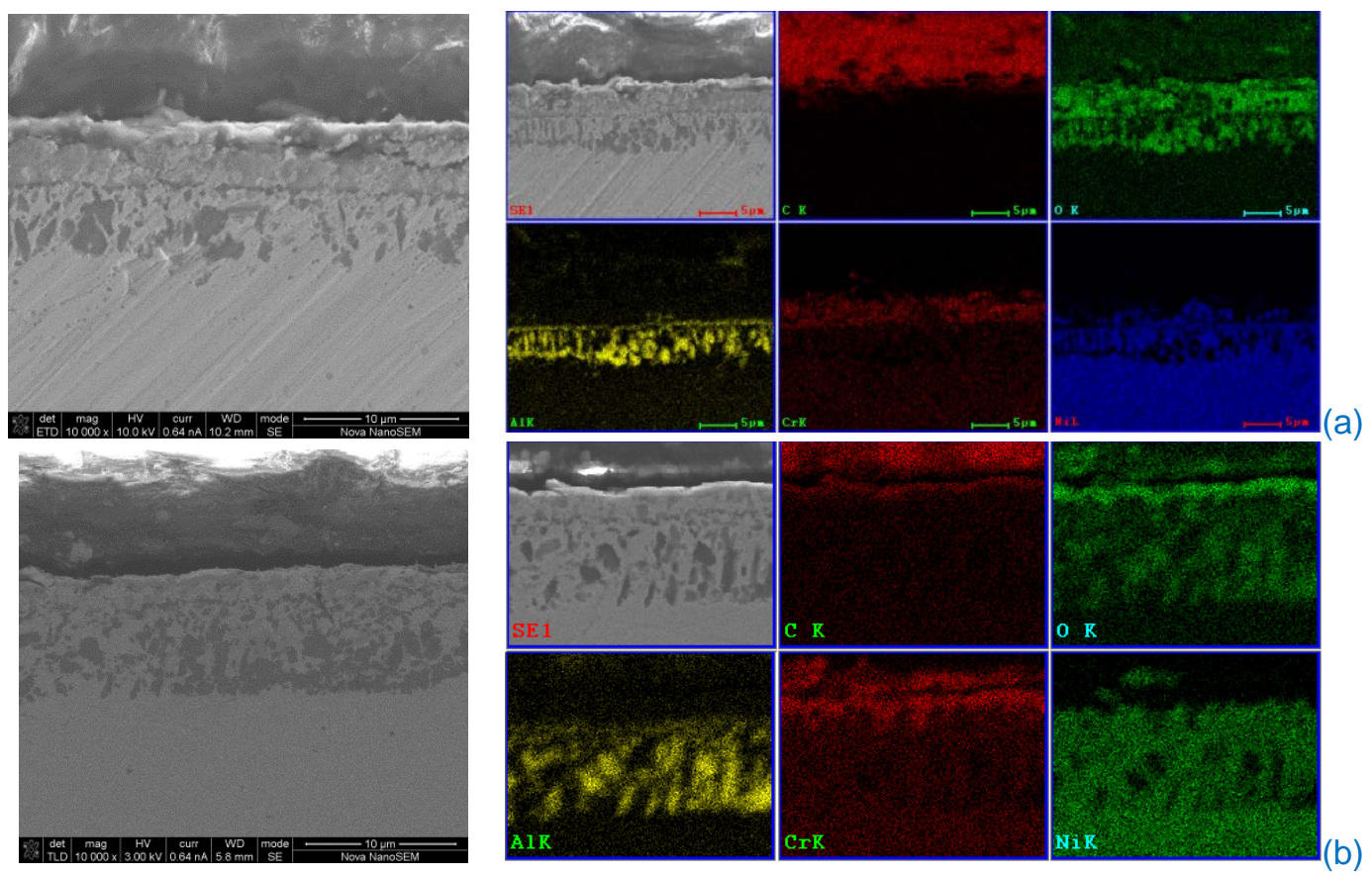

2 
1 Fig. 5.
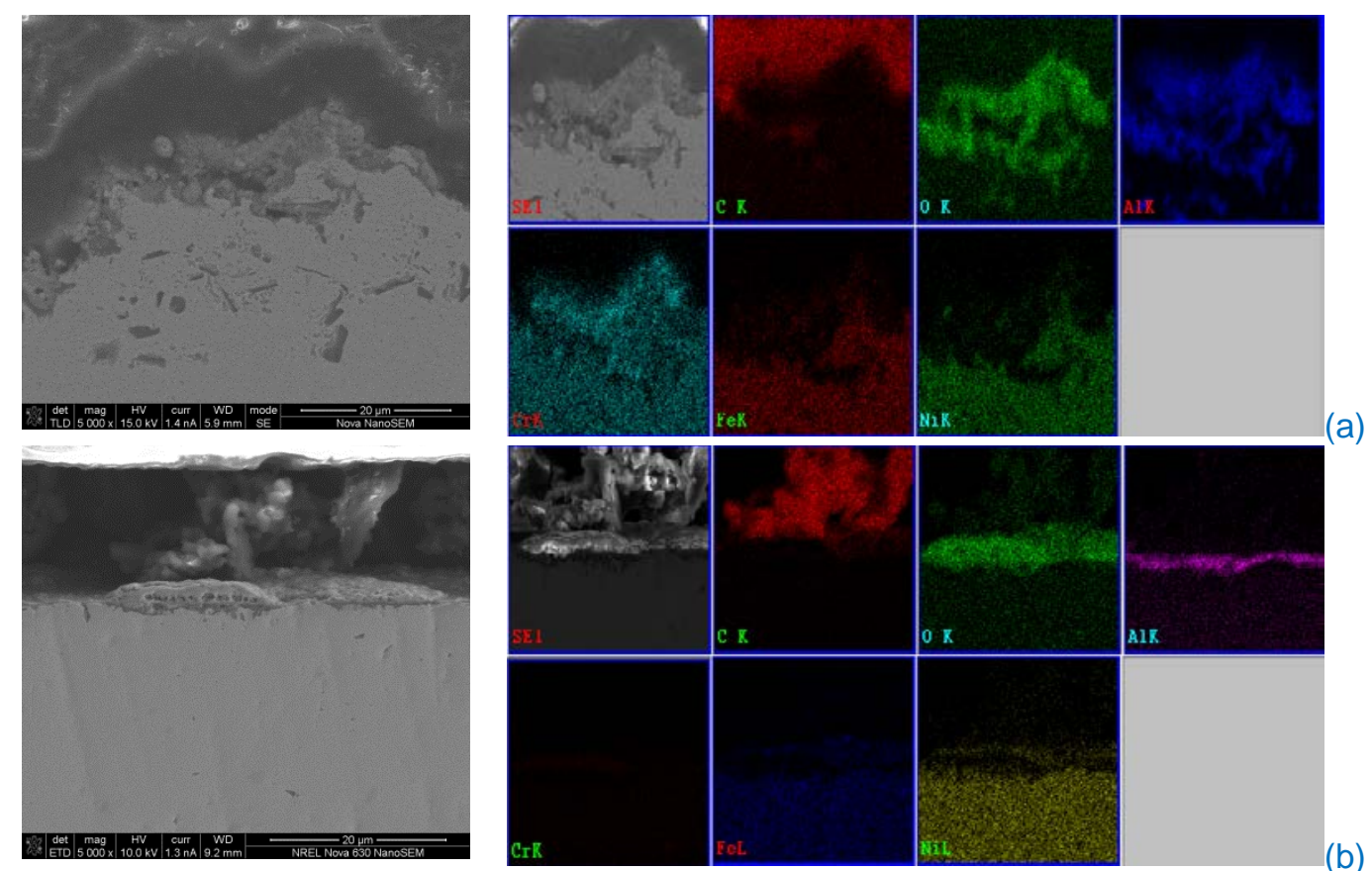

2

3 
1 Fig. 6.
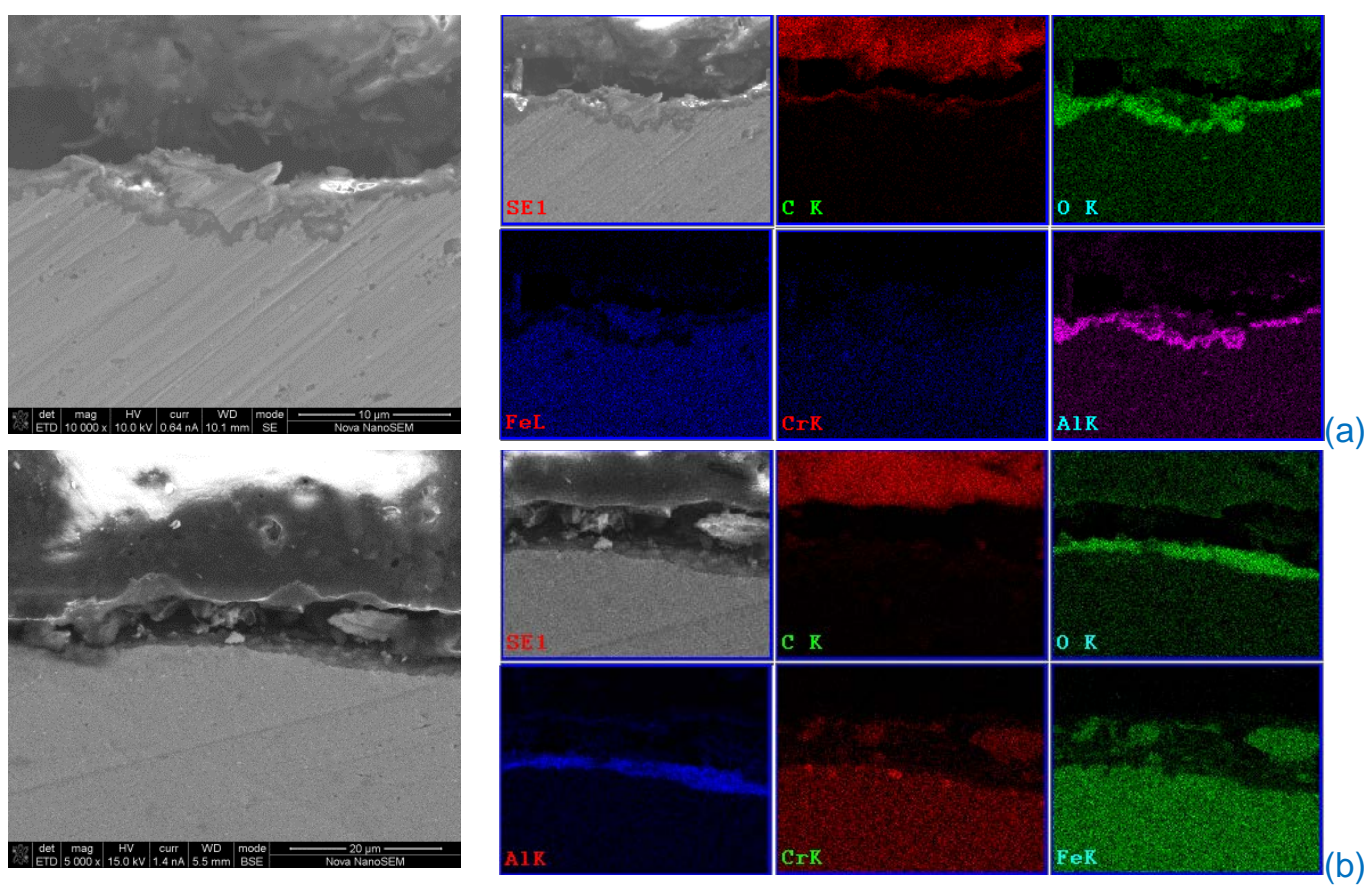

2

3 
Fig. 7.

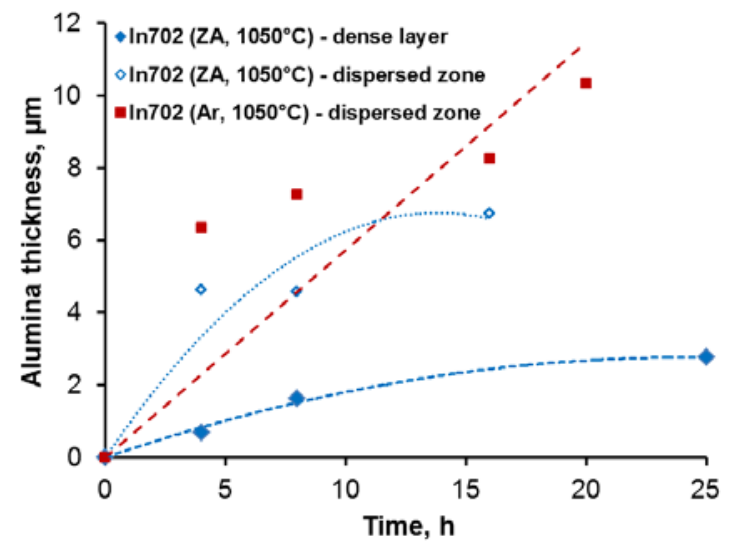

(a)

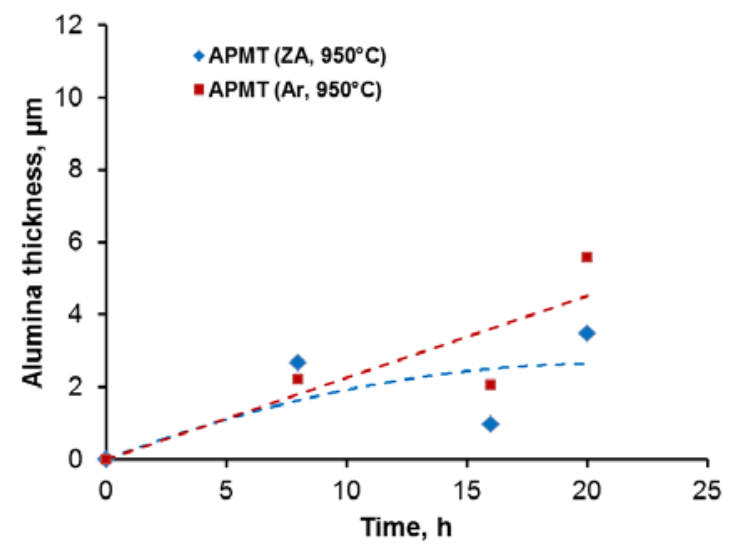

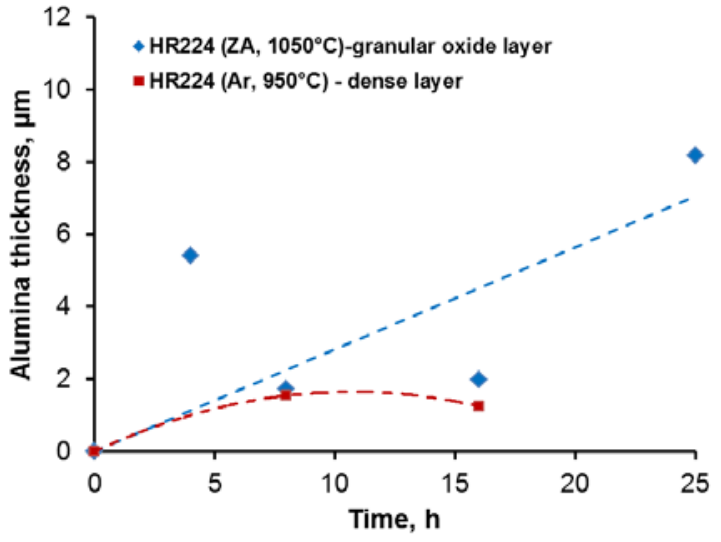

(b) 
$1 \quad$ Fig. 8.

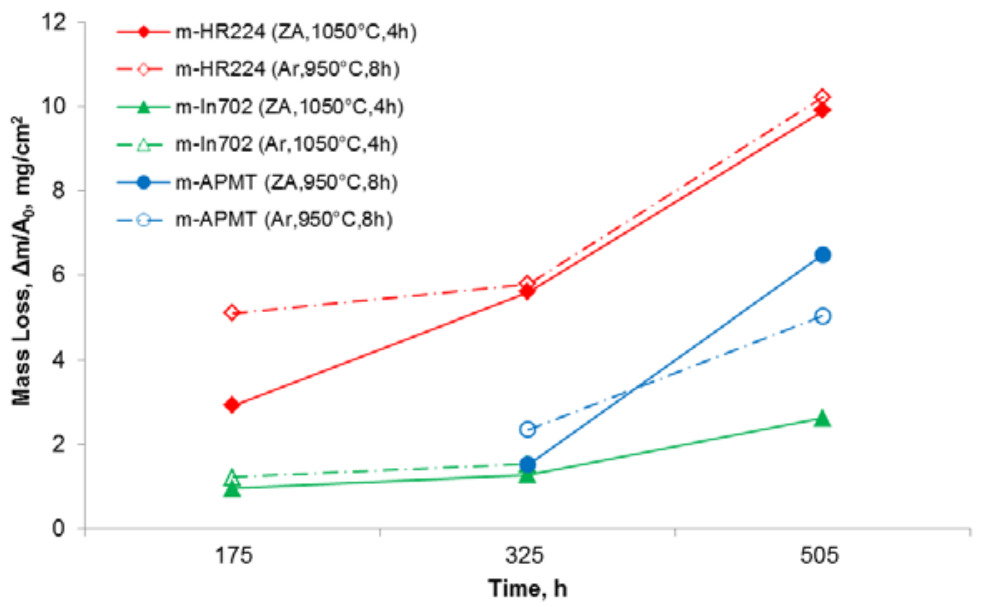

(a)

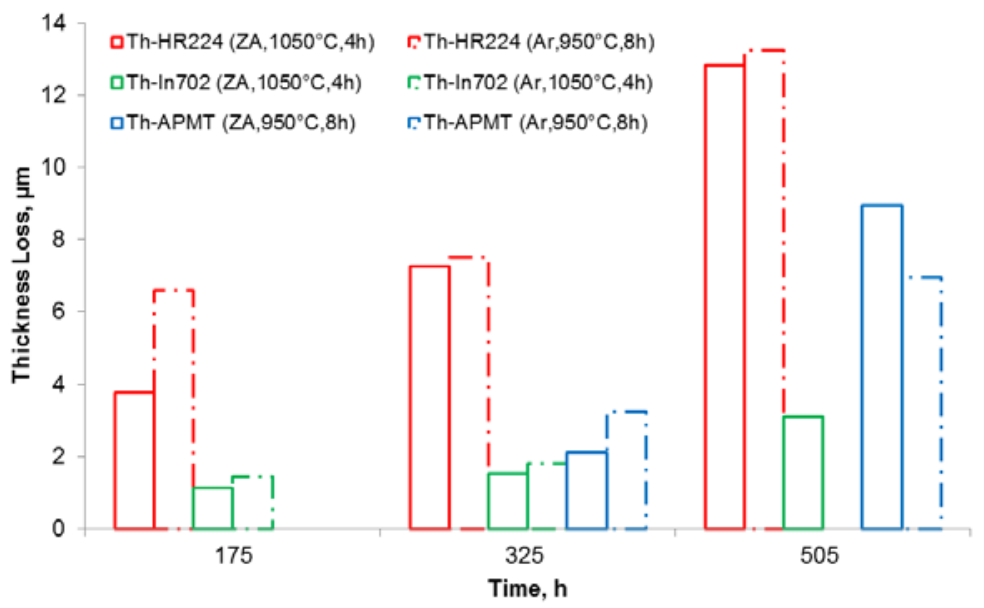

(b)

2 
$1 \quad$ Fig. 9.

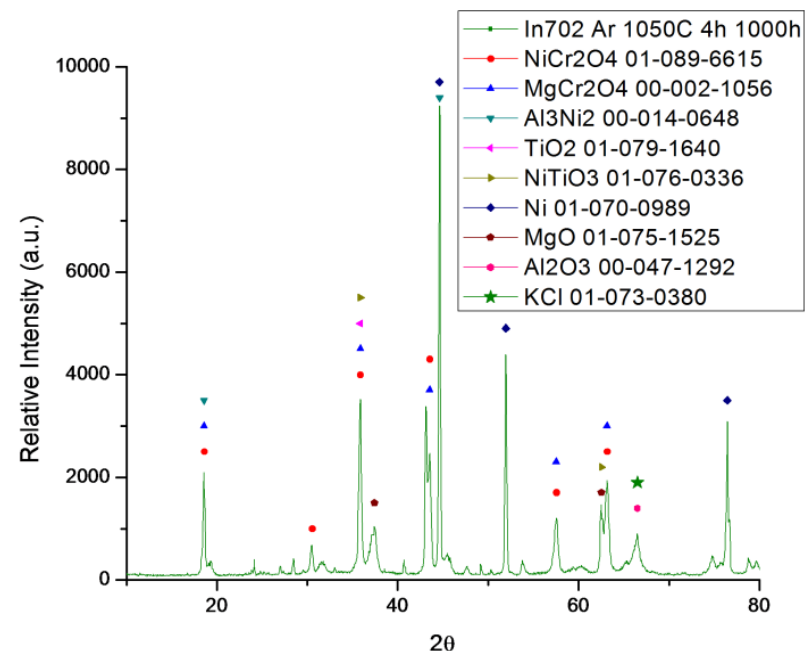

(a)

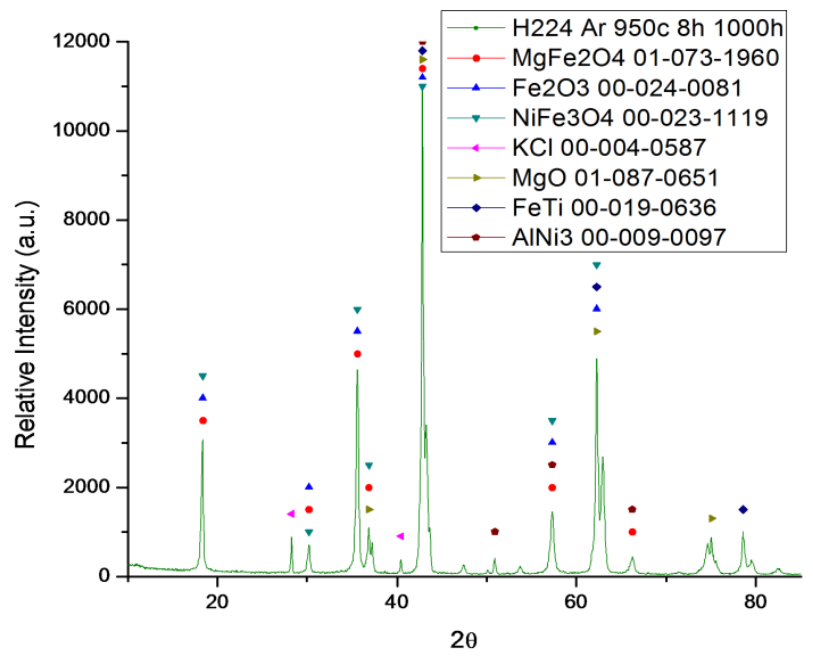

(b) 
1 Fig. 10.
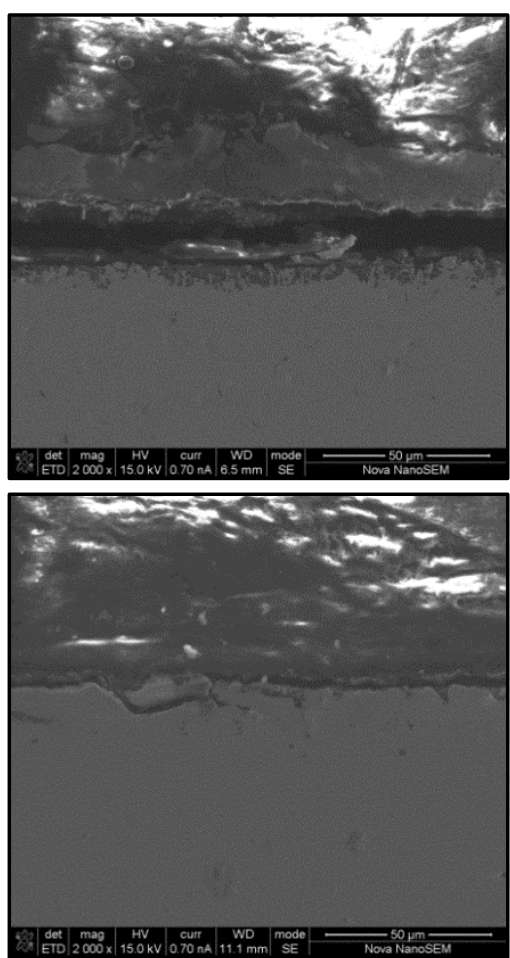
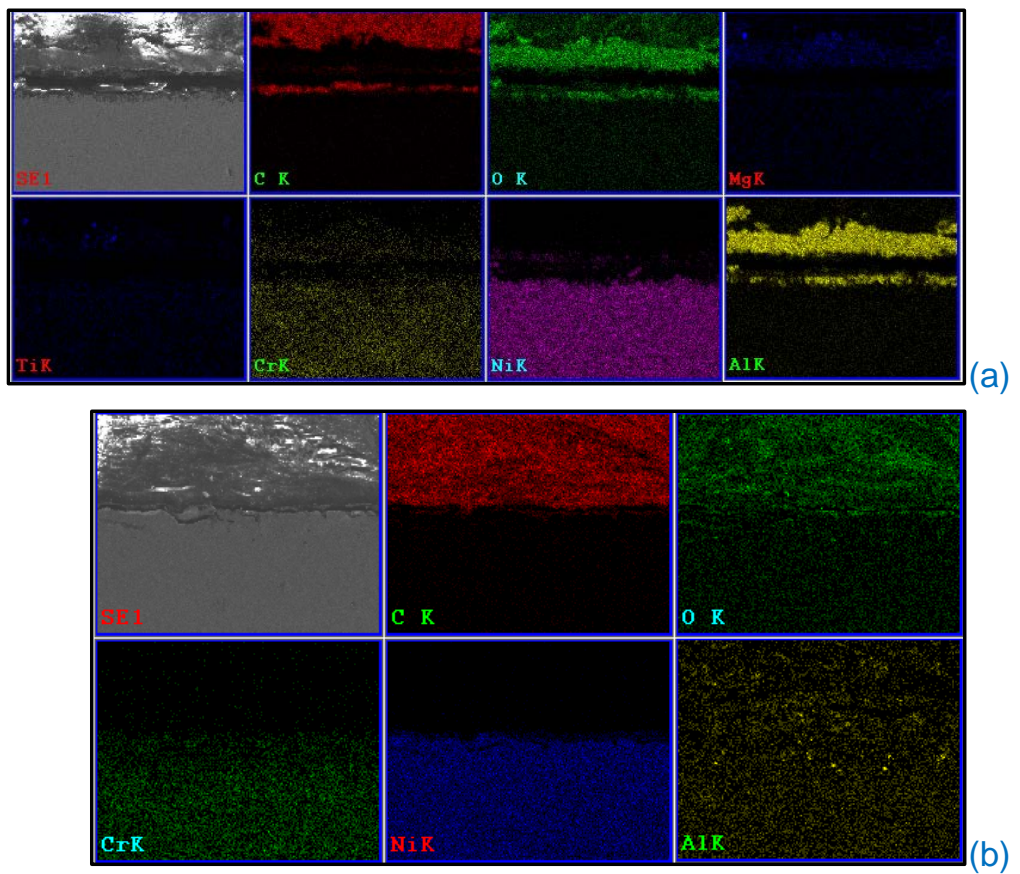
1 Fig. 11.
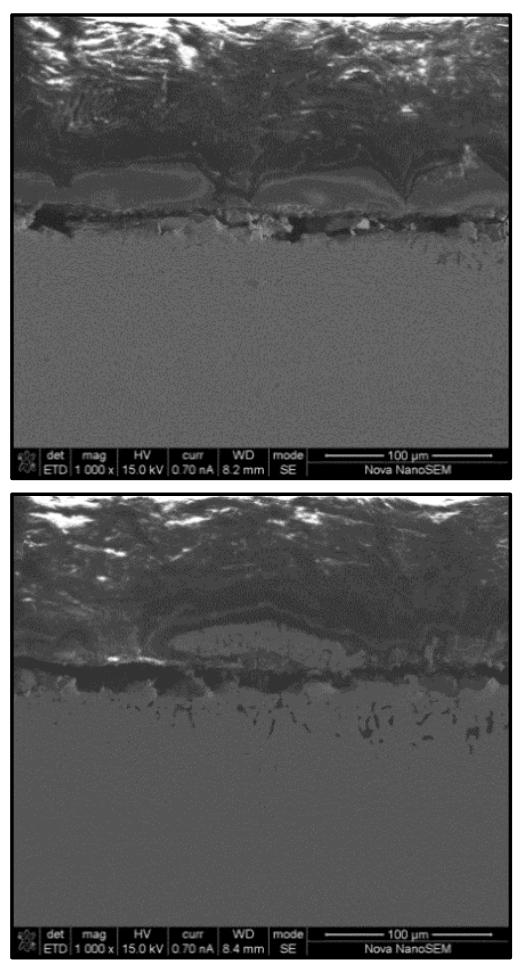
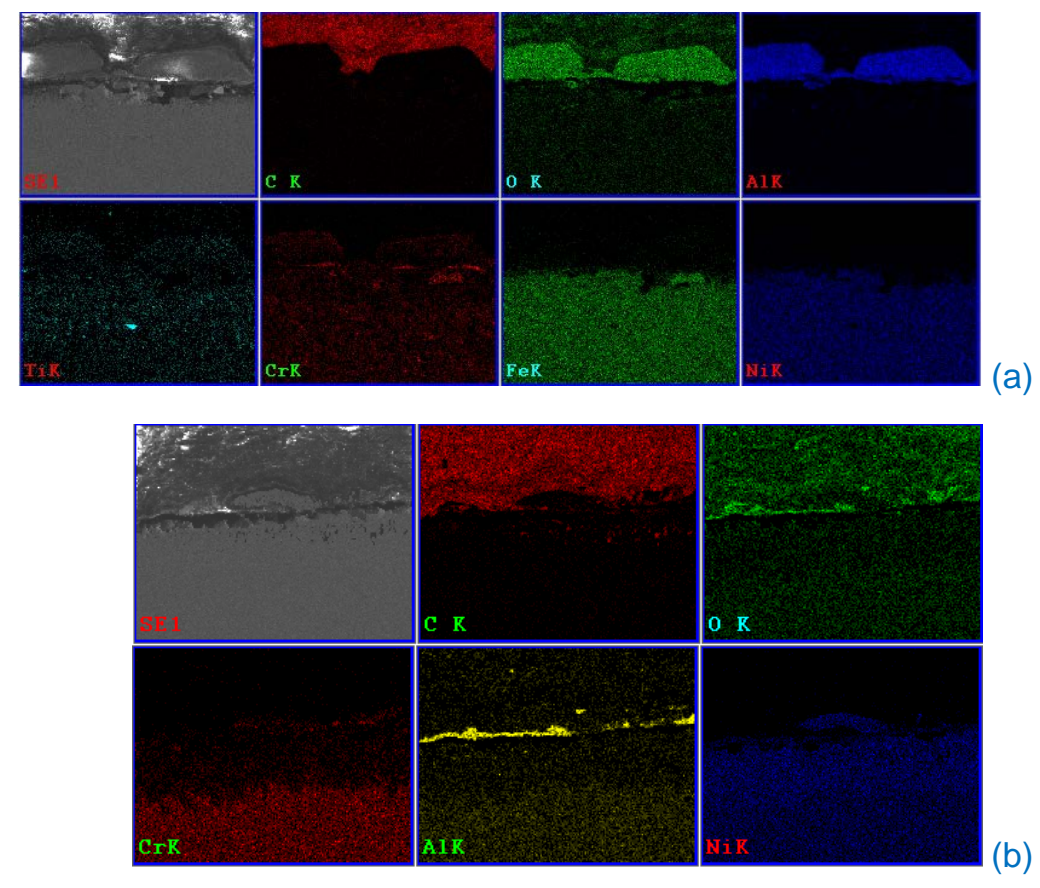
1 Fig. 12.
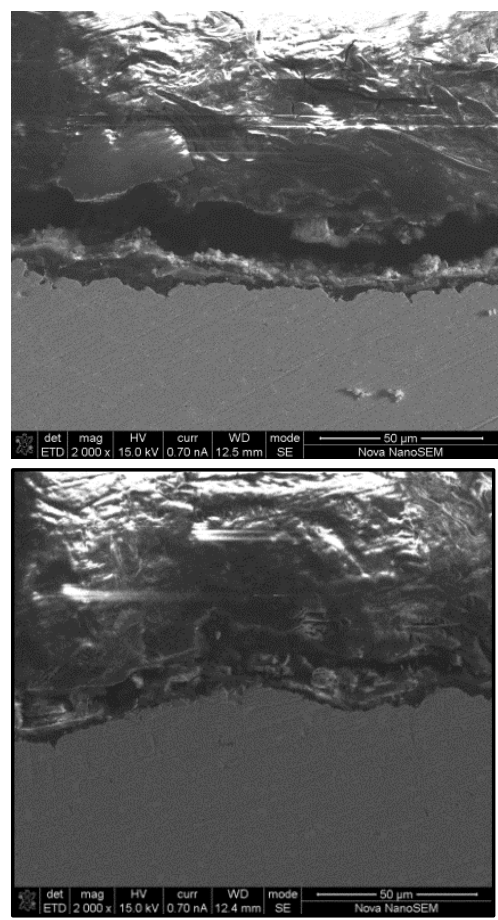

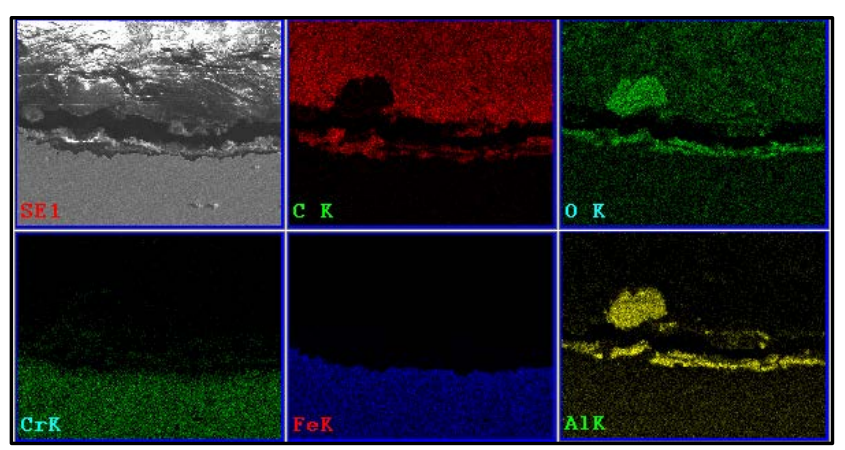

(a)

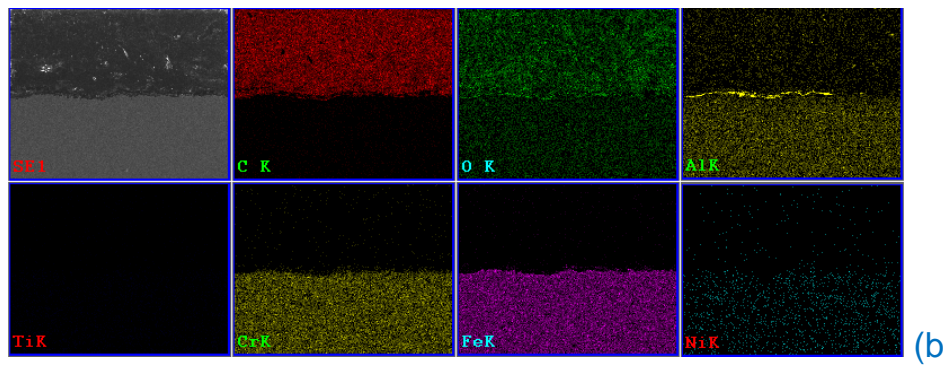


Fig. 13.
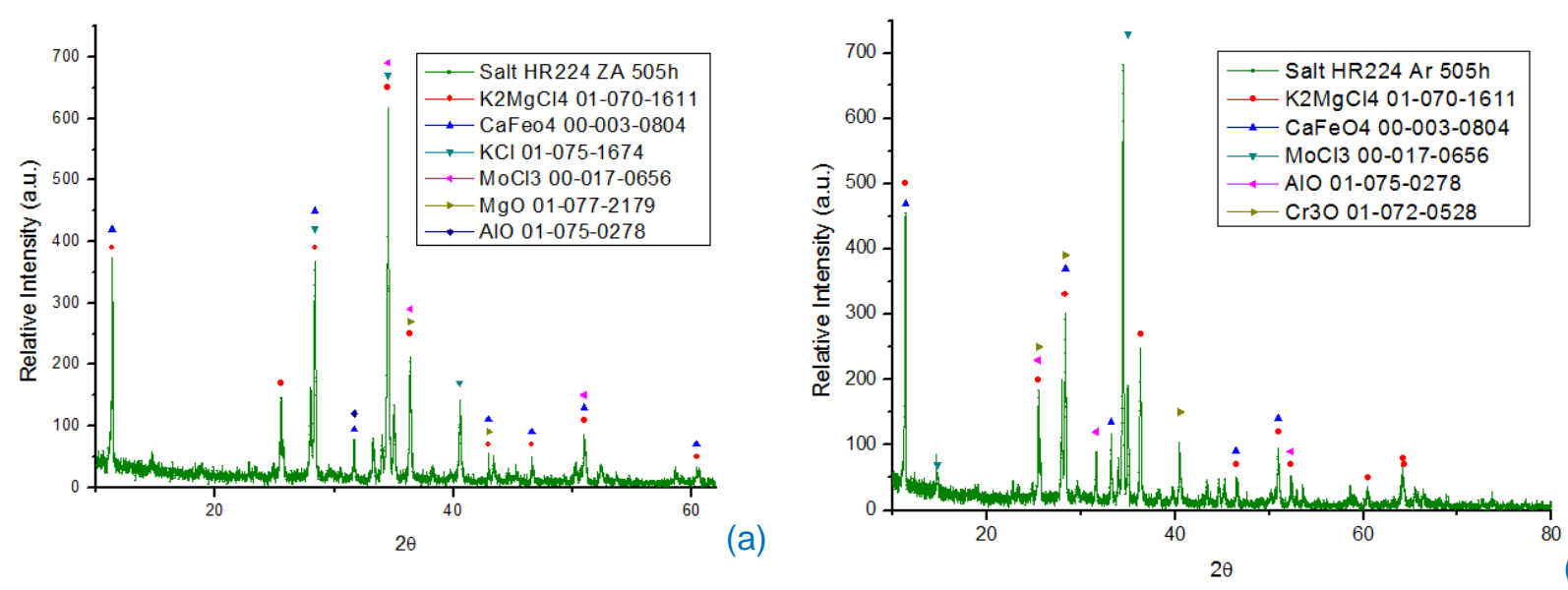

(b)
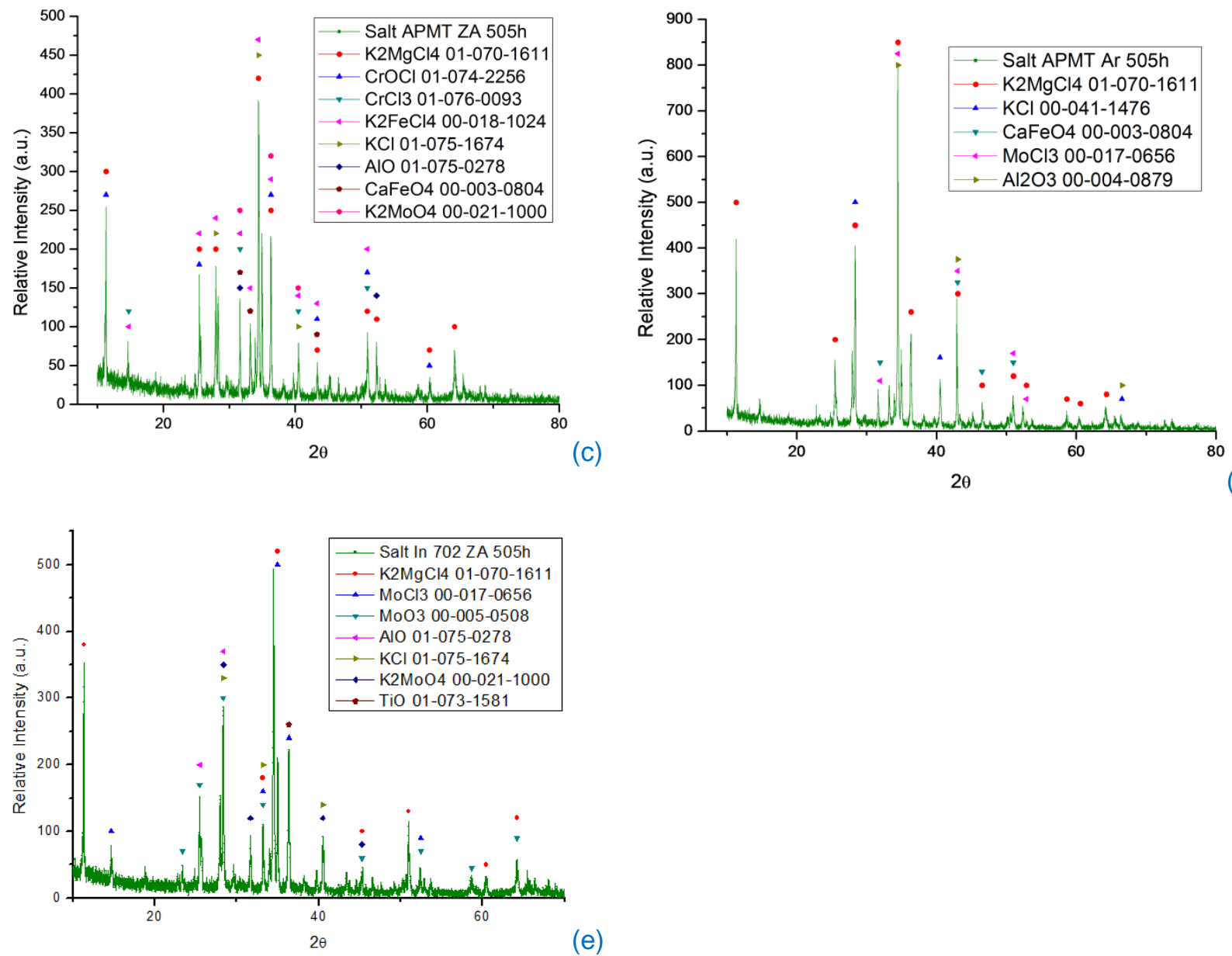

(e) 
$1 \quad$ Fig. 14.
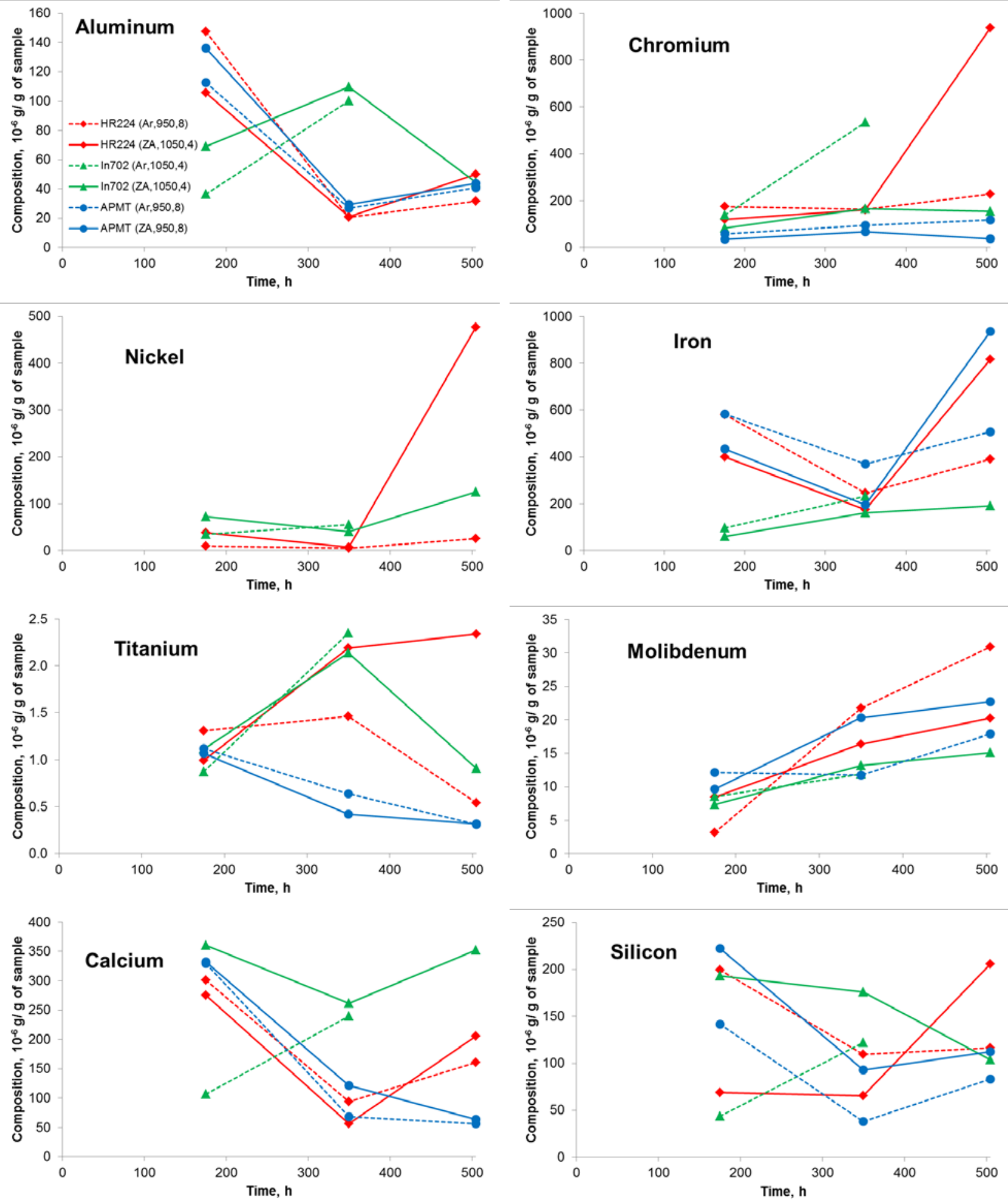